\title{
Substantial Decrease in Contaminant Concentrations in the Sediments of the Venice (Italy) Canal Network in the Last Two Decades-Implications for Sediment Management
}

\author{
Roberto Zonta ${ }^{1, *}$, Daniele Cassin ${ }^{1} \mathbb{(}$, Roberto Pini $^{2}{ }^{\mathbb{C}}$ and Janusz Dominik ${ }^{1} \mathbb{C}$ \\ 1 Consiglio Nazionale delle Ricerche, Istituto di Scienze Marine (CNR-ISMAR), Arsenale Tesa 104, \\ Castello 2737F, 30122 Venezia, Italy; d.cassin@ismar.cnr.it (D.C.); janusz.dominik@ve.ismar.cnr.it (J.D.) \\ 2 Consiglio Nazionale delle Ricerche, Istituto di Ricerca sugli Ecosistemi Terrestri (CNR-IRET), Via Moruzzi, 1, \\ 56124 Pisa, Italy; roberto-pini@cnr.it \\ * Correspondence: r.zonta@ismar.cnr.it
}

Received: 7 June 2020; Accepted: 8 July 2020; Published: 11 July 2020

\begin{abstract}
The Venice canal network requires periodic intervention to remove sediments that progressively accumulate. The most recent dredging operation was carried out in the second half of the 1990s and early 2000s. These sediments had accumulated over a period of more than 30 years and were highly contaminated with $\mathrm{Cd}, \mathrm{Cu}, \mathrm{Hg}, \mathrm{Pb}, \mathrm{Zn}$ and PAHs. Sediments deposited after the dredging work were investigated in 2005, 2009, 2014 and 2017 by analysing sediment cores collected from three sites in the canal network. Arsenic, heavy metal and PAH concentrations were observed to be much lower than past values, although $\mathrm{Cu}, \mathrm{Hg}$ and $\mathrm{PAH}$ levels were still relatively high. The high $\mathrm{Cu}$ concentrations (mean $161 \mathrm{mg} \mathrm{kg}^{-1}$ ) are partly due to the widespread use of Cu-based antifouling paint. Current Italian regulations forbid the disposal of dredged sediments with these concentrations inside the lagoon, thereby increasing the cost of canal network maintenance.
\end{abstract}

Keywords: sediment quality; copper; mercury; lead; PAHs; urban pollution; dredging

\section{Introduction}

The urban environment is a major source of pollutants, including heavy metals and polycyclic aromatic hydrocarbons (PAHs). Nriagu and Pacyna [1] emphasised the importance of metal emissions from cities in the global pollution budget; Dat and Chang [2] recently reviewed anthropogenic sources of PAHs emitted to the atmosphere and highlighted higher PAH concentrations in urban and industrial sites than rural or remote locations. When the urban environment is intimately connected with a water body (river, lake, estuary, coastal waters), the latter may become the final receptor of such pollution, with water quality affected and contaminated sediment accumulating on the bottom [3-12]. Contaminated sediments pose a risk to the overlying waters and biota. When excavation or dredging is necessary, national guidelines stipulate disposal procedures, based on the level of contamination [13].

There is, thus, a need to identify both sources and sinks of pollutants within the urban environment, taking account of the functioning of each city. In this framework, some cities with a close relationship to water have highly distinctive features. An example of such a city is Venice (Italy), whose canal network is "marine in nature" [14] and subject to the unavoidable progressive silting up due to the accumulation of sediments, which are also polluted. The continuous inputs of particles from the surrounding lagoon waters, together with organic and inorganic materials delivered by the urban system, settle on the bottom of the canals due to the weak hydrodynamics and the intricate morphology. Consequently, 
periodical dredging has been performed since ancient times in order to preserve water flow, navigation and hygiene.

During a long period without excavation from the 1960s to the 1990s, a layer of excess sediment up to $1 \mathrm{~m}$ thick accumulated in the canals. Comprehensive restoration of the network started in the mid-1990s and ended in the early 2000s, involving the removal of about $3.5 \times 10^{5}$ metric tons of excess sediments. To determine the disposal procedures, sediment quality was investigated before dredging began by analysing samples collected at 800 sites evenly distributed throughout the network. On the basis of a protocol from the Italian Ministry of the Environment [15], the sediments were classified as highly polluted, particularly because of their heavy metal $(\mathrm{Cd}, \mathrm{Cu}, \mathrm{Hg}, \mathrm{Pb}, \mathrm{Zn})$ and PAH concentrations [16]. The sediment that had accumulated in the canal network was, therefore, recognised as a major environmental problem for the city.

The dredging was part of comprehensive engineering works for the maintenance of the canals and the improvement of urban utilities, including the restoration of building foundations, the introduction of several small wastewater treatment plants, and the renewal of septic tanks and the culvert system [17]. After the dredging, new sediment began to accumulate, providing a good opportunity to study recent trends in pollutant concentrations and evaluate potential approaches to pollutant load reduction. This paper describes the results of a series of investigations carried out between 2005 and 2017 at three selected sites to assess the quality of the new sediments being deposited on the canal beds, by analysing grain-size distribution and heavy metal and PAH concentrations in the sediment cores.

The principal objectives of this work were to: (1) evaluate the efficiency of sanitation measures by comparing contaminant concentrations in past and recent sediments in the canal network; (2) estimate the proportions of contaminants originating from external and internal sources; (3) provide a preliminary assessment of contamination level in respect to sediment quality guidelines, with implications for excavated sediment management.

\section{Site Description}

In terms of its hydrodynamics, geomorphology, ecology, pollution and drainage basin, the environmental characteristics and functioning of the Venice Lagoon (Figure 1a) have been extensively described elsewhere [18-28].

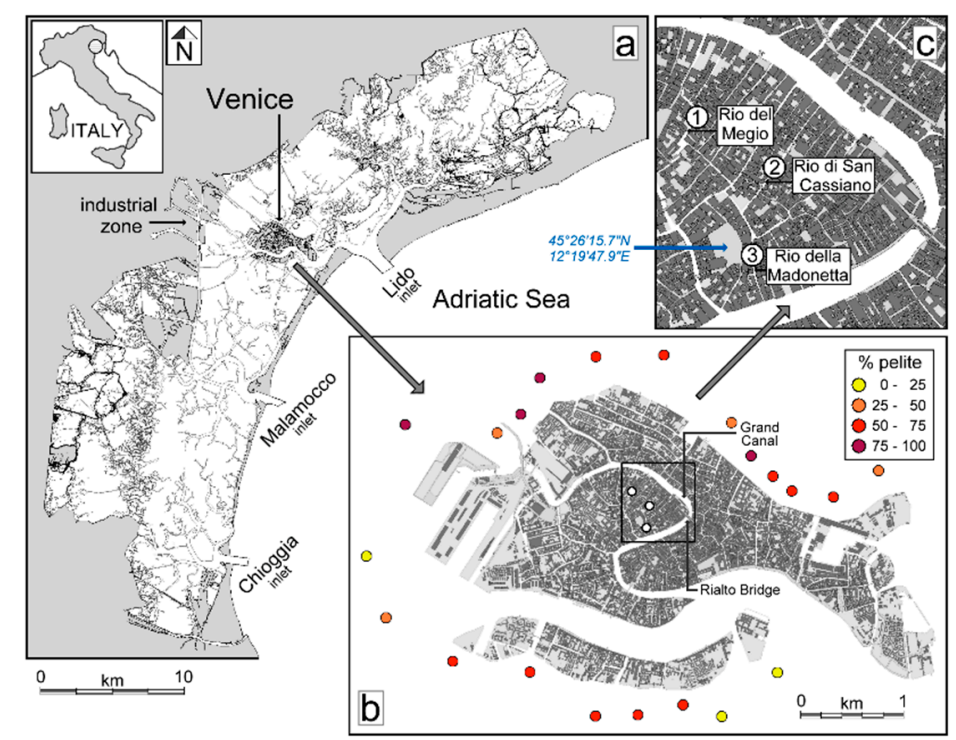

Figure 1. Map of the Venice Lagoon (a) with tidal channels branching out from the three seaward inlets. The City of Venice (b) with sampling sites surrounding the city where sediments were investigated in a previous study ([27], see Section 4.4); percentages of pelite (diameter $<63 \mu \mathrm{m}$ ) in the $0-5 \mathrm{~cm}$ sediment layer are shown. The locations of the three sampling sites for this study are shown in (c). 
The City of Venice (Figure $1 \mathrm{~b}$ ), which has a surface area of $6.3 \mathrm{~km}^{2}$, is located in the central part of the shallow lagoon, and it is built on 119 small islands separated from each other by an intricate $40 \mathrm{~km}$-long network of about 160 interlinked tidal canals (known as 'rii'). The city has a population of 54,000 , a daily flux of about 45,000 commuters and an additional average daily presence of ca. 60,000 tourists. The primary economic activities in the city are commerce and tourism; craft workshops and small boatyards are also present. The city has no cars, but boat traffic is intense in some parts of the canal network.

The canal network accounts for a surface area of $0.43 \mathrm{~km}^{2}$ (plus the $0.25 \mathrm{~km}^{2}$ of the Grand Canal) and has a mean width of $10 \mathrm{~m}$ (ranging from 3 to about $50 \mathrm{~m}$ ). If dredged regularly, the mean depth of the canals is around $2 \mathrm{~m}$, in order to ensure the adequate operation of the network. The hydrodynamics of the network are driven by tidal forcing, as a consequence of phase lags and level gradients at the city boundary. The flood tide propagates from the Lido seaward inlet of the lagoon towards the landward shore, generating a flow from approximately SE to NW [29]. Water exchanges on the western side of the city are mainly driven by the Grand Canal, which is directly connected to the Lido inlet by first order tidal channels. In contrast, the flow on the eastern side is mostly from south to north during the flood tide. Opposite flows are typically observed during the ebb phase, although significant differences in water circulation can be induced by meteo-marine conditions. The tidal excursion is typically 80 and $30 \mathrm{~cm}$ under spring and neap tide conditions, respectively, and the average salinity in the network is around $30 \mathrm{psu}$. Current speed is low, from a few $\mathrm{cm} \mathrm{s}^{-1}$ in the more confined branches up to a few tens of $\mathrm{cm} \mathrm{s}^{-1}$ in situations of a high hydrodynamic field. Particulate matter transported from the lagoon by the tidal flux tends to settle within the canal network, especially when the tide is turning, and the network behaves as a trap for suspended particles.

Due to its distinctive urban structure, Venice has no efficient sewage treatment system, and untreated sewage effluents from a large number of diffuse sources are discharged directly into the canals. Organic and inorganic matter is discharged via the multitude of domestic and commercial freshwater effluents, such as food waste through kitchen sinks. Other inputs of matter include inorganic particles originating from the erosion/corrosion of buildings and other urban surfaces-as well as a small contribution from atmospheric deposition [16] — which are transferred to the canals directly or by rainwater through a widespread network of culverts. Based on the most realistic assumptions [30], the contribution of matter from the urban system is responsible for $15-33 \%$ of the overall silting up of the canal network.

Water traffic contributes to pollution of the network due to fuel combustion and the abrasion of boats' protective coatings. In addition, boat traffic in some areas of the network induces resuspension events that remobilise particles and associated pollutants from the canal bottom.

\section{Materials and Methods}

Three study sites were selected in three canals named Rio del Megio (site 1), Rio di San Cassiano (site 2), and Rio della Madonetta (site 3) (Figure 1c). They are located in a central area of the city on the inside of the main meander of the Grand Canal, not far from the Rialto Bridge. Hydrodynamics in this sector are governed by water exchanges with the Grand Canal, flowing from south to north during the flood tide and vice versa during the ebb tide. The investigated sites are among the medium-to-small canals of the network, in terms of dimensions and hydrodynamics, and have little motorboat traffic. They were selected because the mean level of sediment contamination measured in the mid-1990s was representative of the canal network as a whole. The investigated sectors of these canals were dredged in the period 2002-2004.

Sediment cores were collected in Plexiglas liners (inner diameter $6.2 \mathrm{~mm}$ ) with a piston corer several times at each site (January 2005 and May 2006 at site 3; June 2005 at sites 1 and 2; November 2009, September 2014, May and October 2017 in all three sites). Short cores $(10-40 \mathrm{~cm})$ were taken in early samplings (2005-2009) and longer cores $(50-75 \mathrm{~cm})$ in the following years. 
Several factors impede the comparison between cores in terms of metal concentrations and sampling time. Small metallic objects (e.g., pins, screws, coins and even small batteries) or metallic fragments were occasionally found in the cores, which can produce metal concentration peaks in the profiles. To remove such "noise", $2 \%$ of samples were discarded.

Another difficulty is the variability of sediment accumulation rates in the canal cross-section. More sediment accumulates at the edges of the canals than in the central part. Cores were collected at a distance of 1-1.5 $\mathrm{m}$ from the canal walls, corresponding to about a quarter of the canal width, which should ideally reflect the average sediment accumulation rate at each site [31]. In addition, the surface of the canal bottom was uneven after the excavation, and boat traffic and the location of domestic sewage discharge points can produce small undulations, resulting in a variable accumulation rate in the longitudinal direction of the canal. Coring artefacts can also occur, in particular causing shortening when long cores are collected with a piston device [32,33]. Although all cores were collected using liners of the same diameter, different core lengths, the degree of compactness of sediments, and the "human factor" (coring operator) may induce some differences in terms of core shortening. The last two factors resulted in $10 \%$ of samples being discarded. All these factors hamper the estimation of the real accumulation rate, and thus, the term "apparent accumulation rate" is used in this paper.

Cores collected in October 2017 were analysed by X-ray computed tomography (CT scan) with a $1 \mathrm{~mm}$ down-core resolution using a Philips (Amsterdam, The Netherlands) MX8000 IDT 16 System (voltage $120 \mathrm{kV}$, scanning dose 314-393 mA). Data were processed with Horos v2.0.2 software (Horos Project, https://horosproject.org/). Tomographic intensity profiles (CT number, expressed in HU, i.e., units on the Hounsfield scale) mainly reflect changes in sediment bulk density and also serve to detect macroscopic particles and sediment core deformations or other coring artefacts [34,35]. CT digital images of the cores, obtained by setting both window level (WL) and window width (WW) to 1000, were visualised by means of both MIP (maximum intensity projection) and MinIP (minimum intensity projection) algorithms, which enable detection of high or low density structures in a given sediment volume, respectively.

Sediment cores were split lengthwise and one half was sampled by selecting layers 1 to $3 \mathrm{~cm}$ thick at different depths along the profile. Samples were passed through a $1 \mathrm{~mm}$ Teflon mesh to remove debris and organic fragments and were carefully homogenised. Water content was determined from an aliquot of sample dried in an oven at $105^{\circ} \mathrm{C}$ until reaching constant weight [36]. Organic matter content was then estimated by loss on ignition (LOI), after heating the sample in an oven at $550{ }^{\circ} \mathrm{C}$ for two hours [37].

An aliquot of about $2 \mathrm{~g}$ of wet sediment collected from cores in October 2017 was weighed and dispersed in distilled water before grain-size measurement with a laser diffraction particle size analyser (Mastersizer 2000, Malvern Instruments, Malvern, U.K.). The instrument provided the volumetric percentage of particles belonging to 100 diameter classes in the range 0.1 to $2000 \mu \mathrm{m}$. Grain-size classification followed [38], as shown in the USGS chart.

Dried $\left(50^{\circ} \mathrm{C}\right)$ sample aliquots were ground to a powder and ca. $30 \mathrm{mg}$ was digested with $8 \mathrm{~mL}$ $\mathrm{HNO}_{3} 8 \mathrm{~N}$ in a microwave oven (Multiwave 3000, Anton Paar, Graz, Austria) [39]. Arsenic, Cd, Cr, Cu, $\mathrm{Fe}, \mathrm{Mn}, \mathrm{Ni}, \mathrm{Pb}$, and $\mathrm{Zn}$ were determined by inductively coupled plasma atomic emission spectrometry (ICP-AES-Optima 2100DV, Perkin Elmer, Waltham, MA, USA) [40]. Mercury analysis was carried out by cold vapour atomic absorption spectrometry (AAS-Analyst 100, Perkin Elmer, USA) [41].

A certified reference material sample (PACS-2-Marine Sediment Reference Materials for Trace Metals and other Constituents, National Research Council of Canada) was digested and analysed several times; mean recovery ranged between $88 \%(\mathrm{Hg})$ and $104 \%(\mathrm{Cd})$, except for $\mathrm{Ni}(77 \%)$, Fe $(75 \%)$, and $\mathrm{Cr}(70 \%)$. The lower recovery of the latter elements suggests that they were bound to refractory minerals (such as alumina-silicates and/or some resistant sulphides).

Although As is a metalloid, when referring to the group of measured elements, the generic name "metals" is used for simplicity. 
For PAH determination, an aliquot of wet sample was air dried in the dark at room temperature for $48 \mathrm{~h}$ on hexane-rinsed aluminium foil, and then, finely ground in an agate mortar. About $2 \mathrm{~g}$ of dried sediment was extracted using a Microwave Sample Preparation System (Multiwave 3000, Anton Paar Graz, Austria), in accordance with USEPA recommendations [42].

Purification and concentration were performed by eluting extracts through glass chromatography columns packed with silica gel/alumina $[43,44]$ and by a rotary evaporator.

In accordance with USEPA recommendations [45], the concentrations of 14 priority PAHs (naphthalene (Naph), acenaphthene (Ace), fluorene (Fl), phenanthrene (Phe), anthracene (Ant), fluoranthene $(\mathrm{Ft})$, pyrene $(\mathrm{Py})$, benzo(a)anthracene $(\mathrm{B}[\mathrm{a}] \mathrm{A})$, chrysene $(\mathrm{Chy})$, benzo(b)fluoranthene $(\mathrm{B}[\mathrm{b}] \mathrm{Ft})$, benzo(k)fluoranthene $(\mathrm{B}[\mathrm{k}] \mathrm{Ft})$, benzo(a)pyrene $(\mathrm{B}[\mathrm{a}] \mathrm{Py})$, dibenzo(a,h)anthracene $(\mathrm{diB}[\mathrm{a}, \mathrm{h}] \mathrm{A})$ and benzo(g,h,i)perylene $(\mathrm{B}[\mathrm{g}, \mathrm{h}, \mathrm{i}] \mathrm{Per}))$ were measured using a high performance liquid chromatograph (HPLC—Series 200, Perkin Elmer, USA) coupled to a programmed fluorescence detector (HP-1046A, Hewlett Packard, Palo Alto, CA, USA).

Grain-size and pollutant concentration data for the sediment dredged from the network between the mid-1990s and early 2000s were obtained from the database of the Municipality of Venice. For both types of analysis, the analytical techniques used were consistent with those adopted in the present study.

Laboratory practices were subject to quality control $[46,47]$. The precision of the instrumental analysis was checked by control charts for each element. ICP-AES and AAS analyses were calibrated using external standards via the standard curve approach. Full calibration was performed after every set of 48 samples. Data quality was monitored using procedure blanks ( $5 \%$ of samples) and sample replicates $(6 \%)$. Blanks indicated that the analytical procedure was free from contamination as the concentrations of all elements examined were below the method's detection limits. The analytical precision checked by replicates was estimated to be better than $5 \%$ for all elements.

PAHs were identified by matching retention times and were quantified from the calibration curves established for each compound by analysing four external standards. The average determination coefficients $R^{2}$ of the calibration curves were greater than 0.99 and the relative standard deviations of the calibration factors were always below $20 \%$ (average $10 \%$ ). The detection limits were in the range $0.05-0.1 \mathrm{ng} / \mathrm{g}$. Blanks were run for the entire procedure. Recovery and accuracy were validated with IAEA-417 and IAEA-159 certified sediment sample reference materials. Recovery was $75-108 \%$ for all PAH congeners except naphthalene. Naphthalene exhibited lower and more variable recovery $(20-40 \%)$, probably due to losses in the two rotary evaporator steps, and thus, results for this compound are not presented here. Laboratory methods were also validated by intercalibration procedures [48].

\section{Results and Discussion}

\subsection{Sediment Characteristics along the Vertical Profile}

The structural characteristics of the three cores collected in October 2017 are shown in Figure 2. CT images (a) and CT number profiles (b) in MIP conditions (maximum intensity projection, ca. $8 \mathrm{~mm}$-thick slab) showed little variation with depth, and thus, only small changes in sediment bulk density. In the upper part of the core from site 1, a diminution of the CT number corresponded to a $5 \mathrm{~cm}$-thick less consolidated sediment layer with higher water content (mean value 55\%) than the rest of the core (48\%). In contrast, higher CT number values were observed in the top $4 \mathrm{~cm}$ at site 3 due to the presence of small shells. Macroscopic particles (from a few $\mathrm{mm}$ to more than $10 \mathrm{~mm}$ in size) were found at a range of depths, but were more abundant in the lower part of the cores. These were mainly stone fragments (debris from walls) and shells (Appendix A, Figure A2). Their presence corresponds to positive peaks in the CT number profiles. Additional information on CT numbers, macroscopic particles, water content and LOI profiles is reported in Appendix A. 


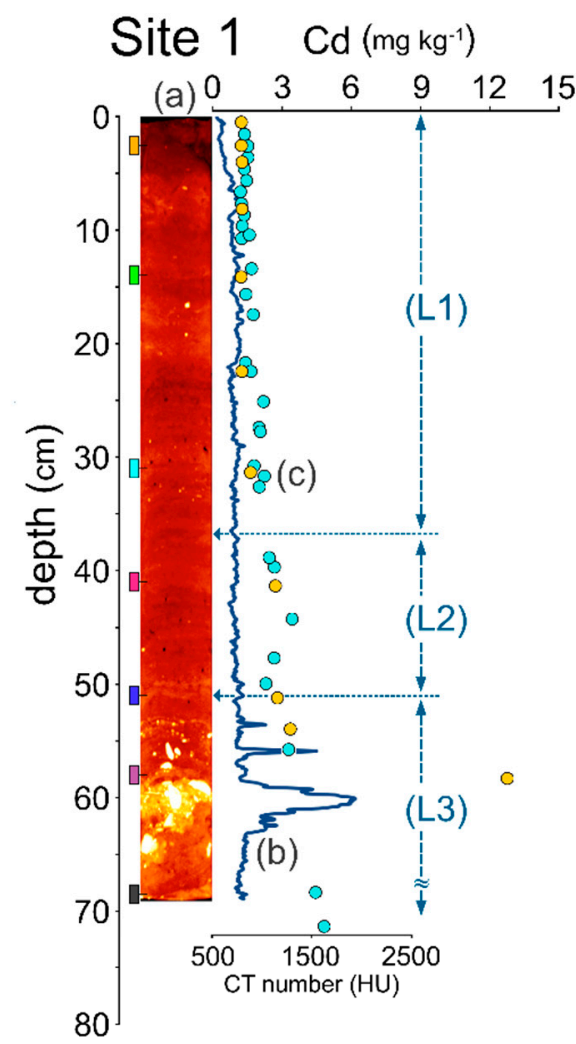

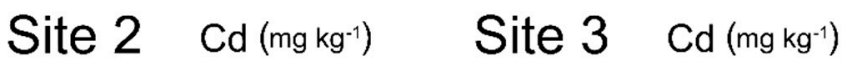
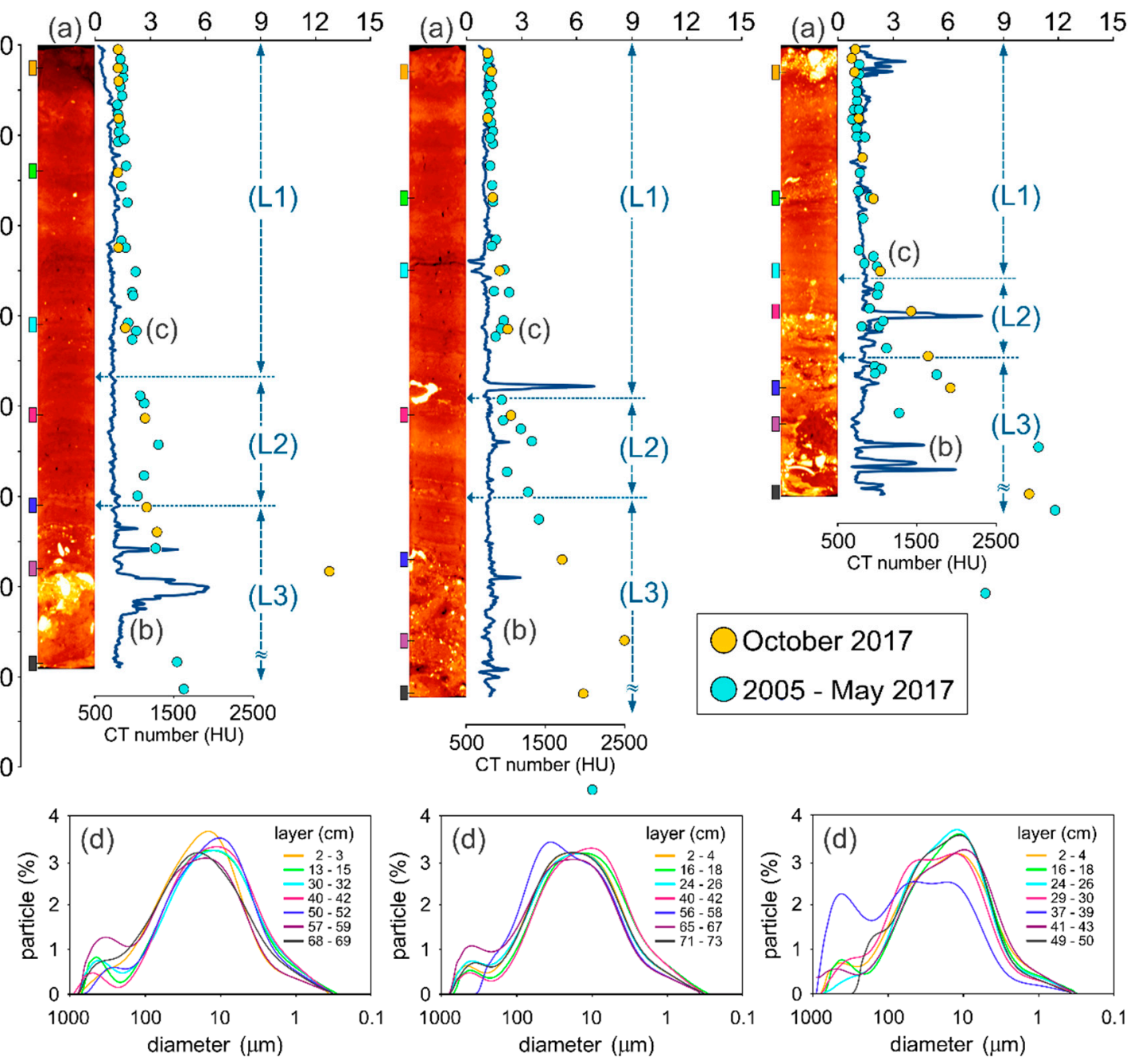

Figure 2. CT images obtained for the cores collected at sites 1, 2 and 3 (October 2017), analysing (a) $7.8 \mathrm{~mm}$-thick slabs (MIP algorithm; black to red-lower density; yellow to white-higher density), and (b) related CT number profiles (dark blue lines) with depth measured in the central vertical axis. Cadmium concentration profile with depth (c) in the cores from October 2017 (yellow circles) and all other cores (blue circles), resulting from the superimposition of data acquired in various samplings over the years. Sediment grain-size spectra (d) in samples from progressive depth intervals, marked on the left of the CT images with coloured rectangles matching the spectra. On the right of each core are numbered sections: (L1) sediment accumulating in the period 2005-2017; (L2) intermediate layer; (L3) old sediment (left after last dredging).

Environmental radionuclides, such as ${ }^{210} \mathrm{~Pb}$ or ${ }^{137} \mathrm{Cs}$, could not be used for the correlation of cores from different periods because of the high accumulation rate, resuspension and dredging of sediments after the Chernobyl spike. In the absence of stratigraphic markers, other than the sediment layer left after dredging (evidenced in the CT image from the cores recovered in October 2017), the correlation between the cores collected at different dates was obtained by matching the metal contents that showed distinct changes with depth. Despite difficulties due to different sampling strategy in various periods and the possible coring artefacts mentioned in Section 3, a coherent picture emerged, allowing for application of a constant shift for each site in respect to the core from October 2017. These shifts correspond to 3.0, 3.2 and $2.0 \mathrm{~cm}_{\text {year }}{ }^{-1}$ multiplied by the time elapsed between October 2017 and the date of core recoveries at sites 1,2 and 3, respectively. An example of the result is shown for $\mathrm{Cd}$ in Figure $2 \mathrm{c}$ and the details of the shift procedure are given in Figure A4 (Appendix A). 
The subdivision of the cores in layers L1, L2 and L3 was based solely on contaminant distribution with depths: L1-low and quasi-constant; L2-intermediate; L3-high and variable concentrations. Metal concentrations in L2 essentially correspond to the concentrations in sediments that overflowed from adjacent sections of the canal once the dredged section was flooded again. This intermediate sediment layer accumulated very early on after the end of the dredging operations and was subsequently mixed with newly settled particles of type L1 once the canal was opened to boat traffic and tidal currents. As the sediments overflowing from adjacent canal sections had comparable bulk density and grain-size distribution to overlying sediments (L1), no markers for the upper limit of L2 can be expected in the CT images. The limit between L1 and L2, based on change in metal concentrations, cannot be precisely determined and the date of reopening of the canals after dredging is not precisely known (sometime between 2003 and 2004). Consequently, the estimated sedimentation rate of recent sediment in L1 is approximate but consistent with previous estimates for the Venice canals of about $2-3 \mathrm{~cm}$ year $^{-1}[30,31]$. As the dredging in the studied canals was finalized at latest in 2004, followed by the overflow from adjacent canal sections, we assumed that normal sedimentation resumed in 2005.

In the layer remaining after dredging (L3), at the bottom of all three cores, a large number of coarse debris were observed on the CT images (Figure 2a) along with a higher percentage of sand particles $(125-1000 \mu \mathrm{m})$ at site $1(57-59 \mathrm{~cm}$ depth) and site $3(37-39 \mathrm{~cm})$, whereas at site $2(56-58 \mathrm{~cm})$, a higher percentage was accounted for by the 25-200 $\mu \mathrm{m}$ fraction (Figure $2 \mathrm{~d}$ ). These features indicated an additional source of sandy material, the result of repair work on buildings and improvements to utility networks, which were carried out while the canal sections were drained. The bottom layers (L3) consist of old sediments with very high concentrations of the majority of metals and PAHs, approaching those determined in the sediment dredged from the canal network after the mid-1990s (Table 1).

Table 1. Mean contaminant concentrations ( $\mathrm{mg} \mathrm{kg}^{-1}$ dry weight), standard deviation (STD) and coefficients of variation (CV\%) determined in the upper core layer (2005-2017) of sediments sampled at three sites (i.e., layer L1 in Figure 2); mean concentrations in the sediment that accumulated before the mid-1990s $(<1995)$ in the canals to which sites 1, 2 and 3 belong $\left({ }^{*}\right.$ obtained from the database of the Municipality of Venice); ratios of present to past mean concentrations (R means) at each site expressed as percentages.

\begin{tabular}{ccccccccccc}
\hline Site & & As & Cd & Cr & Cu & Hg & Ni & Pb & Zn & PAHs \\
\hline \multirow{4}{*}{1} & Mean (2005-2017) & 8.3 & 1.55 & 28.3 & 178 & 2.02 & 20.6 & 68.0 & 329 & 2.2 \\
& STD & 0.8 & 0.30 & 2.6 & 23 & 0.27 & 2.4 & 6.6 & 27 & 0.5 \\
& CV $\%$ & $10 \%$ & $19 \%$ & $9 \%$ & $13 \%$ & $13 \%$ & $12 \%$ & $10 \%$ & $8 \%$ & $24 \%$ \\
& Mean $(<1995)^{*}$ & 33.3 & 9.62 & 55.9 & 358 & 5.30 & 35.7 & 302.0 & 2014 & 12.8 \\
& R means & $25 \%$ & $16 \%$ & $51 \%$ & $50 \%$ & $38 \%$ & $58 \%$ & $23 \%$ & $16 \%$ & $17 \%$ \\
\hline & Mean (2005-2017) & 7.9 & 1.48 & 26.4 & 159 & 2.25 & 18.8 & 64.8 & 324 & 1.3 \\
& STD & 0.6 & 0.33 & 2.2 & 12 & 0.35 & 1.0 & 8.4 & 40 & 0.4 \\
& CV $\%$ & $8 \%$ & $23 \%$ & $8 \%$ & $8 \%$ & $15 \%$ & $5 \%$ & $13 \%$ & $12 \%$ & $31 \%$ \\
& Mean (<1995) * & 29.4 & 8.81 & 57.1 & 288 & 4.76 & 34.6 & 293.7 & 1525 & 4.4 \\
& R means & $27 \%$ & $17 \%$ & $46 \%$ & $55 \%$ & $47 \%$ & $54 \%$ & $22 \%$ & $21 \%$ & $31 \%$ \\
\hline & Mean (2005-2017) & 7.0 & 1.81 & 24.7 & 146 & 2.21 & 17.5 & 66.5 & 339 & 3.3 \\
& STD & 0.7 & 0.44 & 2.0 & 8 & 0.52 & 0.7 & 11.4 & 63 & 1.0 \\
& CV $\%$ & $11 \%$ & $24 \%$ & $8 \%$ & $5 \%$ & $23 \%$ & $4 \%$ & $17 \%$ & $19 \%$ & $29 \%$ \\
& Mean $(<1995) *$ & 26.8 & 7.41 & 57.0 & 401 & 3.73 & 53.9 & 278.3 & 2098 & 9.9 \\
& R means & $26 \%$ & $24 \%$ & $43 \%$ & $36 \%$ & $59 \%$ & $33 \%$ & $24 \%$ & $16 \%$ & $33 \%$ \\
\hline
\end{tabular}

Sediment grain-size distribution (Figure 2d) was characterised by high silt content (4-63 $\mu \mathrm{m}$ ) at a range of depths, with a mean percentage of $67 \%$ for all three cores. The principal mode was within the fine silt range $(10-15 \mu \mathrm{m})$ for almost all samples. A secondary mode corresponding to the sand fraction was present in most samples, but was more pronounced in deeper sediments, where macroscopic debris was also frequently observed. The grain-size distribution curves in the lower $20 \mathrm{~cm}$ in core 3 varied more than the other cores.

The grain-size distributions of the sediments that accumulated in the period 2005-2017 and before the mid-1990s (which were dredged) were broadly similar (Figure 3). This remarkable stability in 
particle dimensions implies that in these canals, no substantial changes in sediment transport and/or particle sources occurred between the two periods. A slightly lower percentage was observed for the clay fraction in recent sediments at site 3 than sites 1 and 2 . This is due to the proximity of site 3 to the Grand Canal, resulting in a higher current field and consequently, a greater capacity for transport and remobilisation of fine particles with tidal currents. This difference in site 3 compared to sites 1 and 2 was also highlighted by the sediment's lower water and organic matter (LOI) content, resulting in a higher bulk density in the CT scan analysis (Appendix A).

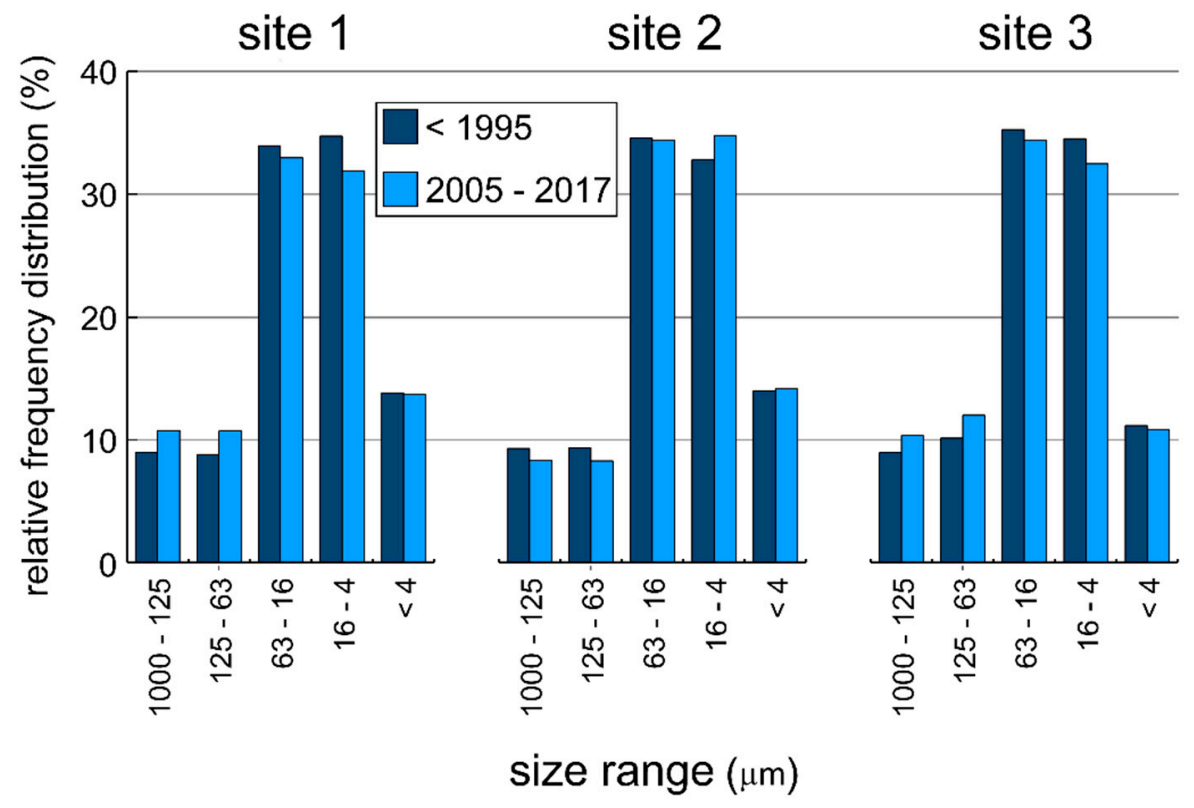

Figure 3. Grain-size comparison between sediments that accumulated before 1995 (mean values measured in the sediments dredged from the canal to which the sites belong) and in the period 2005-2017 (mean values in layer (L1 in Figure 2)), for the three sites. Coarse to fine sand (1000-125 $\mu \mathrm{m})$; very fine sand $(125-63 \mu \mathrm{m})$; coarse to medium silt $(63-16 \mu \mathrm{m})$; fine to very fine silt $(16-4 \mu \mathrm{m})$; clay $(<4 \mu \mathrm{m})$.

\subsection{Contaminants in Recent and Past Canal Sediments}

The depth profiles of contaminants (Figure 4), particularly As, $\mathrm{Hg}, \mathrm{Pb}, \mathrm{Zn}, \mathrm{PAHs}$ and, to a lesser degree, $\mathrm{Cu}$ showed similar features to $\mathrm{Cd}$. Chromium and Fe concentrations were only slightly higher in the deep layers, and Ni concentrations were remarkably similar across depths and sites.

The mean concentrations of all metals in the layer L1 that accumulated after 2005 were similar at the three sites (Table 1), with differences ranging from $5 \%(\mathrm{~Pb}, \mathrm{Zn})$ to $20 \%(\mathrm{Cd}, \mathrm{Cu})$. It can, therefore, be assumed that the sites were not affected by major point sources of metal contaminants and that the determined concentrations are representative of sediment contamination in the investigated sector of the canal network.

Table 1 also shows the level of contamination in the sediment that accumulated in the period before the mid-1990s, expressed as the mean concentration in the canal to which the site belongs. Ratios of present to past concentrations are also reported (as percentages). In the post-dredging period (2005-2017), concentrations fell to ca. 20\% of previous levels for Cd and $\mathrm{Zn}$; ca. 25\% for As, Pb and PAHs; ca. 47\% for $\mathrm{Hg}, \mathrm{Cu}, \mathrm{Cr}$ and $\mathrm{Ni}$. Some contaminant concentrations (e.g., Cu, Cr, Ni, Zn) in sediments that accumulated before 1995 in the canal to which site 3 belongs showed considerable deviations from normal distribution, with the mean exceeding the median. Thus, the ratios of means underestimate the true change. Considering the median values (not shown), the ratios are closer to those obtained for the other two canals. 
concentration $\left(\mathrm{mg} \mathrm{kg}^{-1}\right)$
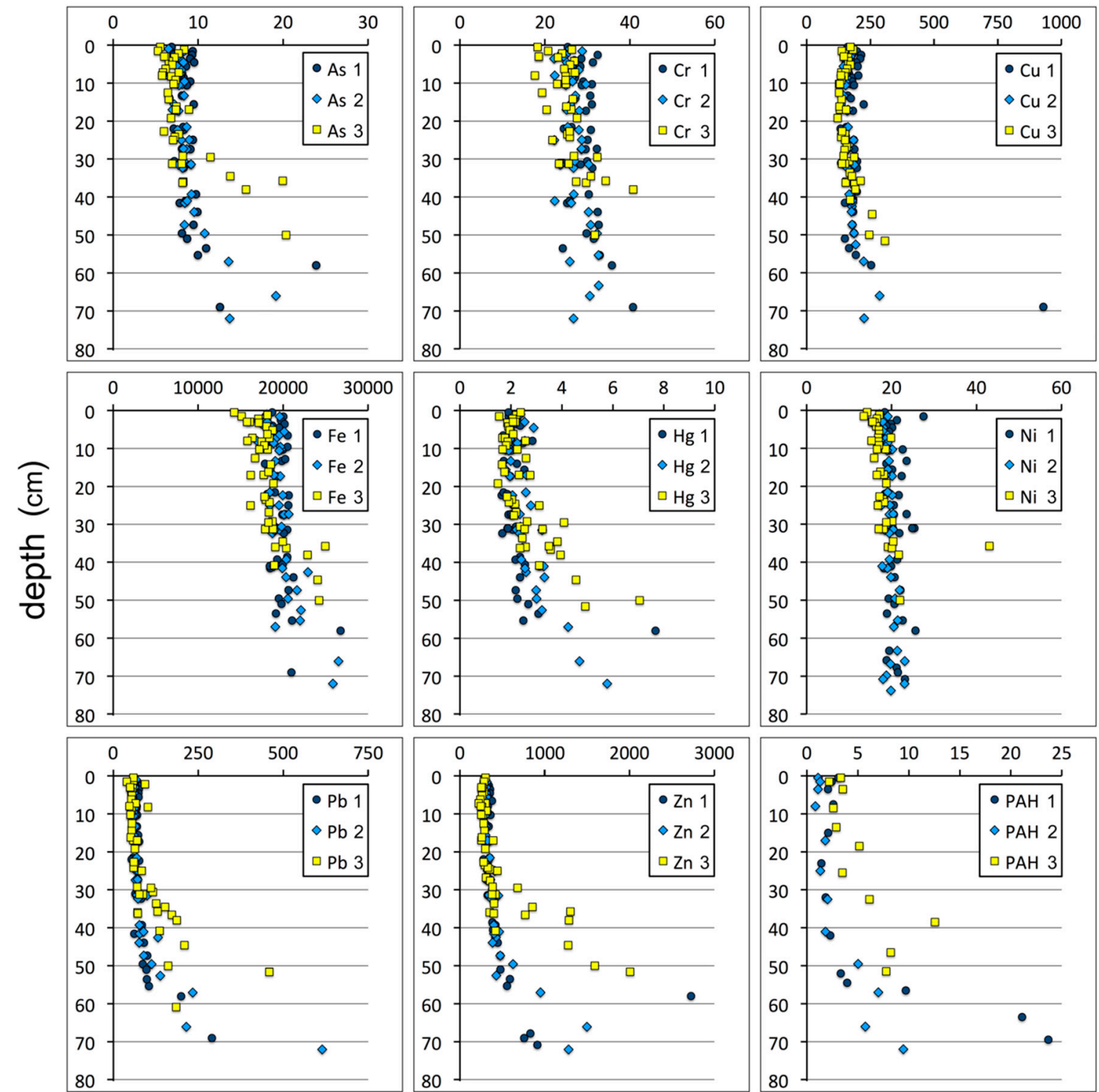

Figure 4. Metal and PAHs concentration profiles with sediment depth, obtained by superimposition of data acquired over the years at three sampling sites. For cadmium's profile, see Figure 2c. Note that at site 3 , the rate of sediment accumulation is smaller, and thus, the increase in pollutant concentrations is observed at a smaller depth as compared to sites 1 and 2.

\subsection{Implication for Sediment Management}

Contaminant concentrations in recent and past canal sediments are compared with local and international Sediment Quality Guidelines (SQGs) in Figure 5. The local SQGs for the Venice canals were established by the Italian Ministry of the Environment [15] in 1993. Based on three progressively higher limits (A, B, C), four classes of contamination are identified which correspond to increasingly stricter rules for the disposal of the dredged sediment. When one or more of the considered species exceeds the upper limit of one class, the sediment is categorised as belonging to the class above (a tolerance of $10 \%$ is permitted when only one species exceeds the limit). 


\section{$2005-2017 \square \square<1995 \quad-$ A --- ERL - B ---ERM -C}

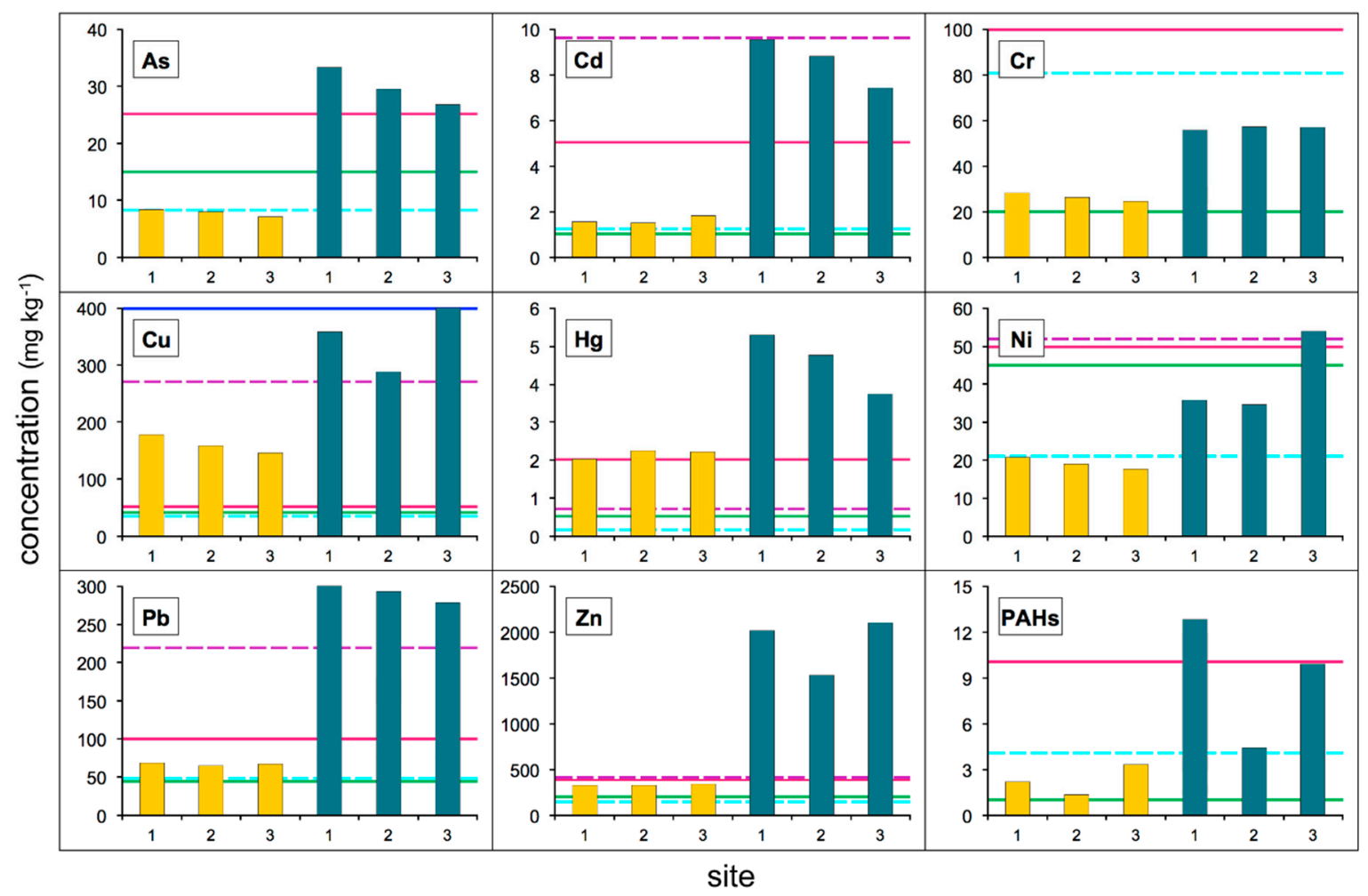

Figure 5. Comparison of mean contaminant concentrations ( $\mathrm{mg} \mathrm{kg}^{-1}$, dry weight) in recent (2005-2017) and past (<1995) canal sediments with local (Italian Ministry of the Environment; limits A, B, C) and international (NOAA; ERL and ERM) Sediment Quality Guidelines (SQGs).

Non-polluted sediment (class 'A') can be used for restoration of the lagoon's morphology (salt marsh reconstruction, reclamation works). Moderately polluted sediment ('B') can also be used for restoration, but only when it is possible to guarantee their permanent confinement in order to protect against the release of contaminants into the lagoon. Polluted sediment (' $\mathrm{C}^{\prime}$ ) can only be used for reclamation of elevated areas that are never in contact with the lagoon water or subject to erosion or dispersion by infiltration. Finally, highly polluted sediment ('>C') must be disposed of in controlled landfills outside the lagoon. The new classification of dredged sediments and the rules of their disposal, based on both ecotoxicological and chemical criteria, are currently in preparation by national and local authorities.

The local SQGs were aimed at classifying the sediment before its removal in order to specify the characteristics and type of disposal site. However, the NOAA guidelines [49] were also considered here, in order to highlight the sediment's potential for causing adverse biological effects and to internationally contextualise the observed pollution levels in terms of three risk levels: an unlikely ecotoxicological risk when concentrations are below the Effect Range Low (ERL) value; a possible risk when concentrations are between ERL and the Effect Range Median (ERM) value; a probable risk when concentrations are above ERM.

Although the concentration of all contaminants was clearly lower than in sediments dredged in the past, the classification of recent sediment in accordance with the local guidelines did not change fundamentally. This is essentially because of the $\mathrm{Cu}$ concentrations, which despite being $50 \%$ lower, are still high enough to put the sediments in class $C$ (ca. three times over the B limit $=50 \mathrm{mg} / \mathrm{kg}$ ), with implications for the cost of disposal after any future dredging. Concentrations of other contaminants, which in the past were in excess of or close to the $\mathrm{B}$ limit, are now well below this limit $(\mathrm{Cd}, \mathrm{Pb}, \mathrm{Zn}$, PAHs) and even the A limit (As). 
Concerning the ecotoxicological SQGs, the ERM limits were exceeded in the past for $\mathrm{Cu}, \mathrm{Hg}$, $\mathrm{Pb}$ and $\mathrm{Zn}$, and $\mathrm{Cd}$ concentrations were just below this limit. In the recent sediments, only $\mathrm{Hg}$ concentrations greatly exceed the ERM limit (ca. four times), and thus, still pose a potential threat to the biota.

\subsection{Sources of Contaminants and Their Evolution}

Contamination in the canal sediments originates from both the city of Venice (internal sources) and resuspended sediments from the lagoon that are transported there by tidal currents and settle in the canals (external sources). To evaluate the level of contamination of sediment particles entering the canal network, heavy metal [27] and PAH [19] concentrations were considered in the surface sediment $(0-5 \mathrm{~cm})$ of twenty-one shallow water sites surrounding the city (Figure $1 \mathrm{~b})$.

All examined contaminants except PAHs showed significant correlations with iron, and therefore, the latter was used as a normalisation factor when comparing different types of sediment $[27,50]$. From Fe-normalised contaminant concentrations, the importance of external sources with respect to the concentration values measured in the three sites within the city canal network can be estimated (Appendix B). Plots of contaminants against Fe concentrations for sediments sampled around Venice showed significant determination coefficients of regression (Figure A6 and Table A1 in Appendix B), whereas similar plots for sediments deposited after 2005 in the three examined canals showed weak or no dependence of contaminants on Fe content. Nevertheless, the ratio of the metal concentrations expected in particles originating from lagoon sediments to the mean concentrations measured in canal sediments makes it possible to estimate the relative importance of internal and external sources. The estimated percentages of metals derived from internal sources are shown in Table 2.

Table 2. Mean concentrations of metals ( $\mathrm{mg} \mathrm{kg}^{-1}$ dry weight), in recent sediments (2005-2017) in three canals compared to expected concentrations in particles originating from lagoon sediments as inferred from metal vs. Fe regressions. The negative percentage value (close to zero) of As indicates the negligibility of sources inside the city for this element (cf. Figure A6a). The estimated contribution of metals from internal sources is also shown. Ratio errors were obtained from the propagation of standard deviations of means and standard errors of regression. Cadmium is not included because data for lagoon sediments are not available in Reference [27].

\begin{tabular}{cccccccc}
\hline & As & $\mathbf{C r}$ & $\mathbf{C u}$ & $\mathbf{H g}$ & $\mathbf{N i}$ & $\mathbf{P b}$ & $\mathbf{Z n}$ \\
\hline (A) Mean 3 canals & 7.7 & 26 & 161 & 2.1 & 19 & 64 & 314 \\
STD & 1.0 & 3 & 22 & 0.3 & 2 & 10 & 44 \\
\hline (B) Lagoon modelled & 8.4 & 20 & 47 & 1.5 & 15 & 31 & 213 \\
error & 2.0 & 3 & 10 & 0.6 & 2 & 7 & 53 \\
\hline 1-B/A; percentage from internal sources & $-9 \%$ & $23 \%$ & $71 \%$ & $27 \%$ & $19 \%$ & $51 \%$ & $32 \%$ \\
error & $2 \%$ & $3 \%$ & $16 \%$ & $12 \%$ & $3 \%$ & $12 \%$ & $8 \%$ \\
\hline
\end{tabular}

As PAHs show no dependence on sediment grain-size, Fe or organic matter content, a simple ratio of mean concentrations in lagoon to canal sediments was adopted. This ratio suggests that $75 \%$ of PAHs in canal sediments originate from internal sources. A similar value was obtained for $\mathrm{Cu}$ (Table 2), but the propagated error of the PAH ratio was very large, mainly due to the high variability of PAH concentrations in the sites surrounding Venice, precluding adequate quantification of local sources.

The substantial drop of sediment contamination observed in the canal network after 2005 can be ascribed to various factors, which have brought about a diminution of internal contaminant sources. These include the use of better building materials and household utensils, the banning of leaded gasoline (European directive, 2002), enhanced citizens' awareness of environmental problems, and-most of all-measures to improve the sewage system implemented concurrently with the dredging operations. Moreover, the reduction in craft and workshop activities in the last decade of the 20th century resulted in lower discharge of metal contaminants from within the city. 
Although $\mathrm{Cu}$ concentrations in recent canal sediments are lower than in sediments deposited before 1995, the contribution of internal sources has remained high, most probably due to the growing use of $\mathrm{Cu}$-based antifouling paints to protect boat hulls, following the ban on tributyltin-based paints.

Increased concentrations of $\mathrm{Cu}$ in the sediments of the Chioggia marina in the southern part of the Venice Lagoon have previously been observed [50]. Cu release from $\mathrm{Cu}$-based antifouling paints is conservatively estimated to be responsible for between 45 and $61 \%$ of internal $\mathrm{Cu}$ flux to the recent sediments of the Venice canal system (for the estimation method, see Appendix C). Further internal sources of copper include roofs and gutters, in-house piping and fungicides [51].

The incidence of internal sources on $\mathrm{Pb}$ concentrations in recent canal sediments is also important, but concentrations have fallen significantly since the ban on leaded petrol was introduced at the beginning of the century. The main source of lead is now the plumbing of traditional houses, where lead pipes have not been replaced with more suitable materials.

The main source of PAHs in the canal network is motorboat traffic. Indeed, $\mathrm{PAH}$ isomer ratios in the sediment samples from the three cores (Ant/Phe $+\mathrm{Ant}=0.52 \pm 0.10 ; \mathrm{Ft} / \mathrm{Py}+\mathrm{Ft}=0.64 \pm 0.13 ; \mathrm{B}[\mathrm{a}] \mathrm{A} / \mathrm{Chy}$ $+\mathrm{B}[\mathrm{a}] \mathrm{A}=0.47 \pm 0.08$; mean \pm std. deviation) indicate pyrogenic origin [52]. The six carcinogenic compounds (B[a]A, Chy, B[b]Ft, B[k]Ft, B[a]Py, diB[a,h]A) [53] account for a large percentage that varies little $(43 \pm 5 \%)$. Another source of PAHs is used cooking oil discarded by domestic and commercial kitchens [54].

PAH input to the canal network strongly decreased in the 1970s, when coal (together with wood and kerosene) was abandoned for heating homes. The significant reduction in the concentration of PAHs observed in recent years is possibly also due to the increasing use of more efficient engines and the limitation of motorboat traffic in some city canals, including the canals investigated in this study.

\section{Conclusions}

Sediment contamination in the Venice canal network is enhanced by its distinctive morphology and hydrodynamics, which trap fine particles transported from the lagoon by tidal flows. The canal network, which accounts for less than $10 \%$ of the city's area, collects a large part of the urban contaminant load, and polluted sediments progressively accumulate on the canal bottom.

Analysis of cores collected from three representative sites in the period 2005-2017, i.e., after the comprehensive dredging of the canal network, showed that concentrations of metals and PAHs were substantially lower than in sediments dredged at the turn of century (1/5 to $1 / 4$ for $\mathrm{Cd}, \mathrm{Zn}, \mathrm{As}, \mathrm{Pb}$ and PAHs; $\frac{1}{2}$ for $\mathrm{Cu}, \mathrm{Cr}, \mathrm{Hg}$ and $\mathrm{Ni}$ ). However, contaminant concentrations have remained fairly constant since 2005. $\mathrm{Cu}$ concentrations are still relatively high with respect to Italian regulations (class $\mathrm{C}$ ), while $\mathrm{Hg}$ concentrations exceed the probable effect level potentially harmful for benthic biota by a factor of 4 .

Because canal sediments trap fine particles transported from the lagoon, a substantial fraction of the total metal load is from external sources. Internal sources are still important for copper, lead and PAHs because of the widespread use of $\mathrm{Cu}$-based antifouling paints, the leaching from water pipes in old houses and motorboat traffic, respectively.

Contamination from copper and to a lesser extent, from $\mathrm{PAHs}$ and $\mathrm{Hg}$, precludes the disposal of dredged sediments inside the lagoon under current Italian regulations. Disposal of the dredged sediments on land clearly increases the cost of canal maintenance. However, it will not be easy to reduce the copper content below the limit for class $C\left(50 \mathrm{mg} \mathrm{kg}^{-1}\right)$, even if the use of Cu-based antifouling paints is discontinued, due to the proximity to this limit of the mean $\mathrm{Cu}$ concentration recorded in the lagoon sediments $\left(47 \mathrm{mg} \mathrm{kg}^{-1}\right)$. In this context, it may be useful to revisit the current regulations in light of state-of-the-art toxicological impact assessments and risk analyses.

Author Contributions: Conceptualization, J.D. and R.Z.; methodology, D.C.; formal analysis, J.D. and R.Z.; investigation, D.C. and R.P.; resources, D.C. and R.P.; writing-original draft preparation, J.D. and R.Z.; writing-review and editing, J.D. and R.Z.; supervision, R.Z.; project administration. All authors have read and agreed to the published version of the manuscript.

Funding: This research received no external funding. 
Acknowledgments: The authors thank Margherita Botter, Gianfranco Magris and Andrea Pesce (CNR ISMAR) for their assistance in sampling and analyses. Andrea Sabino contributed to the analysis and data processing of sediment cores collected in October 2017, as part of his thesis. We acknowledge the help of Irene Guarneri, who identified the mollusc species in the cores. The Municipality of Venice kindly provided data on the grain-size distribution and heavy metal concentrations of the sediment that was dredged from the mid-1990s to the early 2000s. Horos is a free and open source code software that is distributed free of charge under the LGPL license at Horosproject.org and sponsored by Nimble Co LLC d/b/a Purview in Annapolis, MD USA. George Metcalf revised the English of the manuscript.

Conflicts of Interest: The authors declare no conflict of interest.

\section{Appendix A. Vertical Profiles of CT Number, Water Content and LOI in the Three Cores-Matching Method of Metal Profiles Down-Core}

Within each core, the vertical CT number profiles tend to overlap (Figure A1), except in the presence of denser objects (such as shells or small debris, Figure A2), which produce density peaks (corresponding to higher CT numbers). Much bigger differences in the mean CT number were observed between cores than between the three profiles in the same core.

The CT images obtained in MinIP conditions (minimum intensity projection (Figure A2)) showed the presence (d) of low density cavities (black voids), particularly numerous in cores 1 and 2 . They were from about 1 to more than $10 \mathrm{~mm}$ in size and most were circular to elliptical in section; the merging of cavities produced larger elongated voids. Their presence matched negative peaks in the CT number profile that disappeared once the projection intensity was increased to a few millimetres in MIP conditions (maximum intensity projection, ca. $8 \mathrm{~mm}$-thick slab; Figure 2 in the main text). We ascribed the cavities to disk-like or oblate spheroidal methane bubbles produced by organic matter decomposition in anoxic sediments [55,56].

Macroscopic debris were separated from sediments and photographed or their 3D images were obtained by CT techniques (Figure A1). Among shell fragments, the following species were identified: Cerastoderma glaucum, Gibbula adriatica, Bittium reticulatum, Chamelea gallina, and Flexopecten glaber.

Water content in core 1 (Figure A3) showed a sharp increase in the top $5 \mathrm{~cm}$, corresponding to a diminution of the CT number (Figure A1). More generally, the lower water and organic matter content in core 3 produced a CT number profile with higher values than cores 1 and 2 , in maximum intensity projection (Figure 2 in the main text).

As discussed in Section 4.1, the correlation between cores collected at different dates was obtained by matching metal contents with depth. Figure A4 describes the method used; core 2 and $\mathrm{Cd}$ concentration are given as an example.

A constant sedimentation rate was assumed for the period 2005-2017, producing a shift down-core of all profiles in respect to the core from October 2017 (Figure A4a), based on the time elapsed between the core collections. Arrows in Figure A4b-e indicate the position of the top of the core after the shift, with respect to the water-sediment interface in October 2017. By varying the sedimentation rate value, with the help of a spreadsheet (Figure A4f), the best match among profiles was obtained, and consequently, the estimation of the sedimentation rate in the site. 

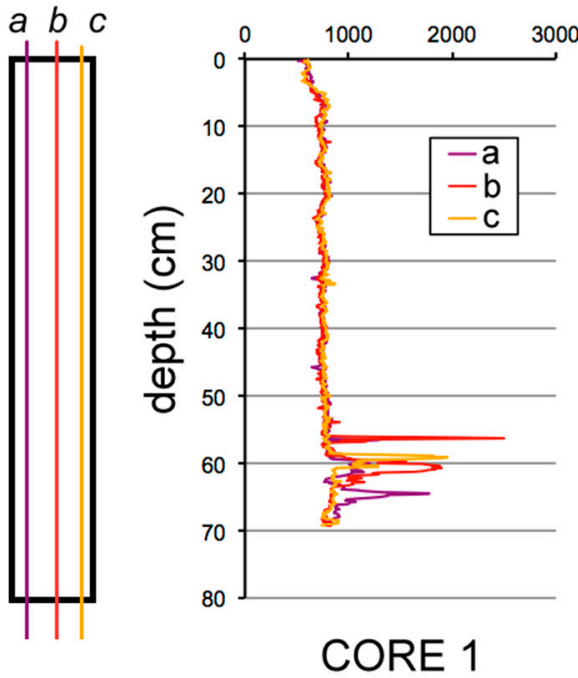

\section{CT-number (HU)}

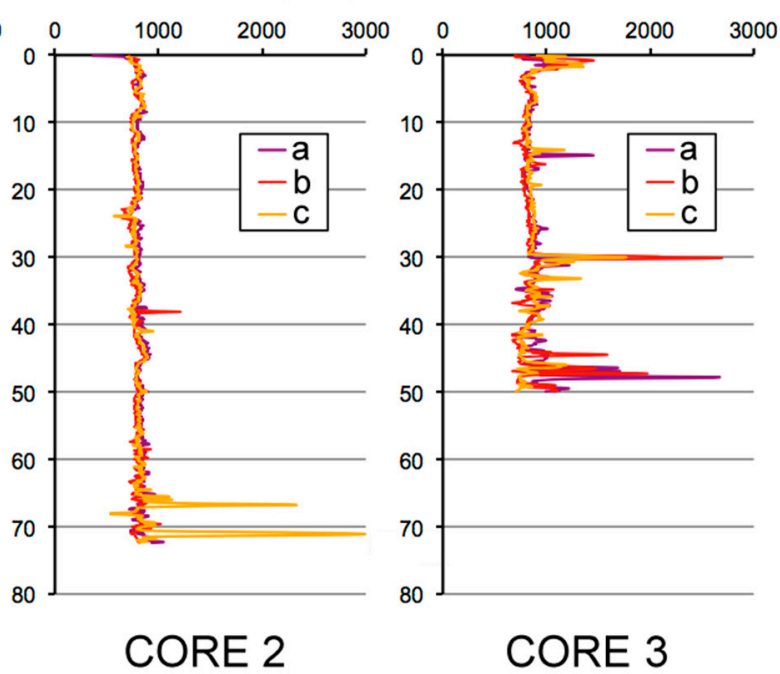

Figure A1. CT number variation along three vertical profiles $(a, b, c)$, in each of the three cores. Data were acquired in MIP conditions (maximum intensity projection) and an $8 \mathrm{~mm}$-thick slab.

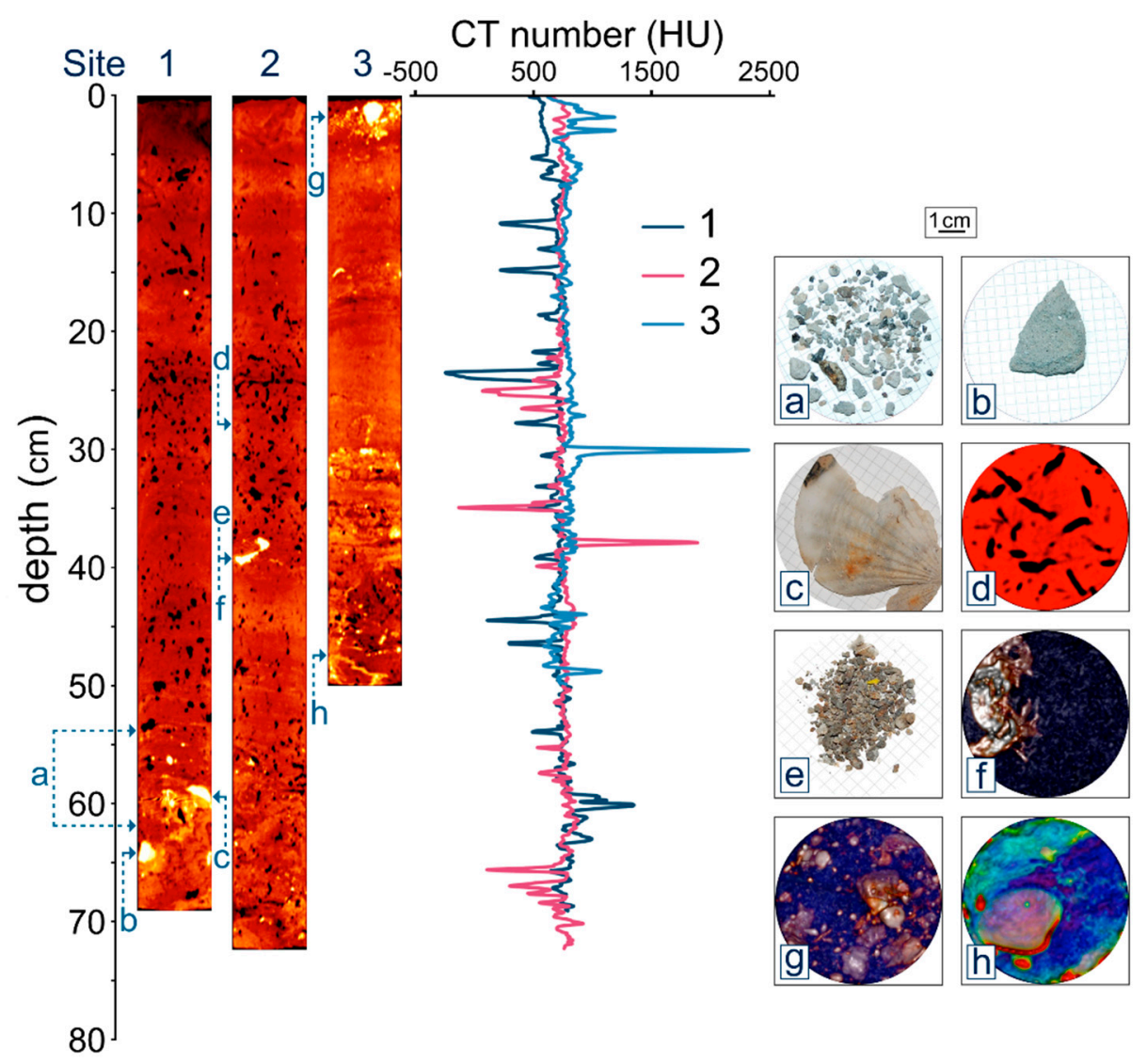

Figure A2. CT images (Horos software) obtained for the cores collected at sites 1, 2 and 3 (October 2017), analysing $1 \mathrm{~mm}$-thick slabs (MinIP algorithm; black to red-lower density; yellow to white-higher density), and related CT number profiles with depth measured in the central vertical axis. Examples of (a) macroscopic debris (small pebbles, shells, coal), (b) a piece of concrete (c) and a shell (Flexopecten glaber) found in the core collected at site 1. Highlighting the presence of gas bubbles (d) in the core collected at site 2; Photograph (e) and CT image obtained by 3D rendering (f) of lamellar debris. CT images from core 3 of (g) small shells and debris in the surface cross section and (h) a shell (3g) (Chamelea gallina), both obtained by $3 \mathrm{D}$ rendering. 


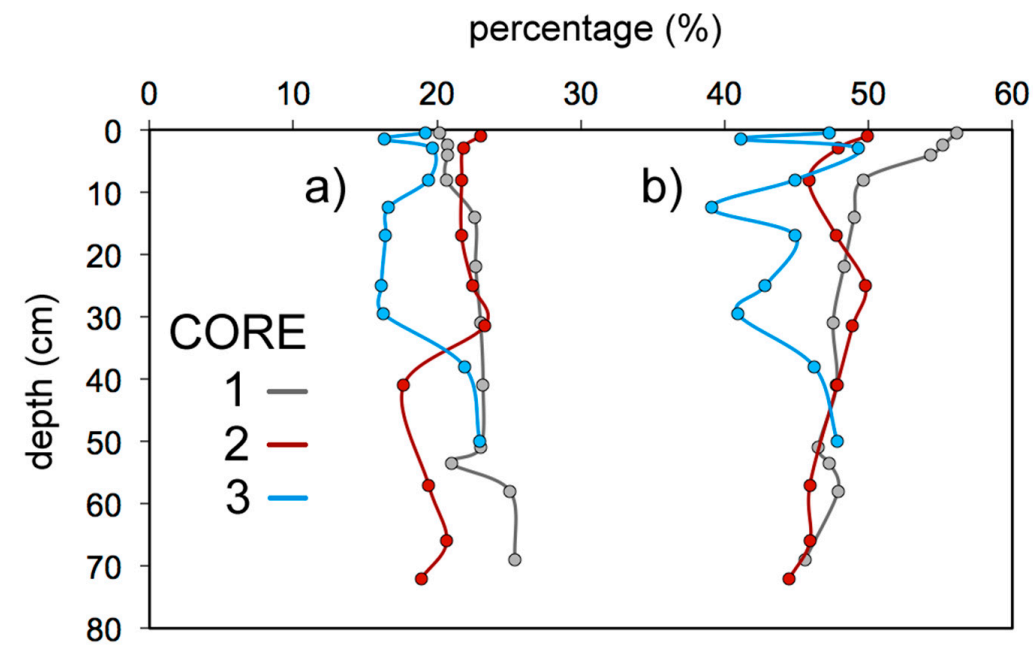

Figure A3. Vertical profiles for LOI (a) and water content (b) in the three cores.

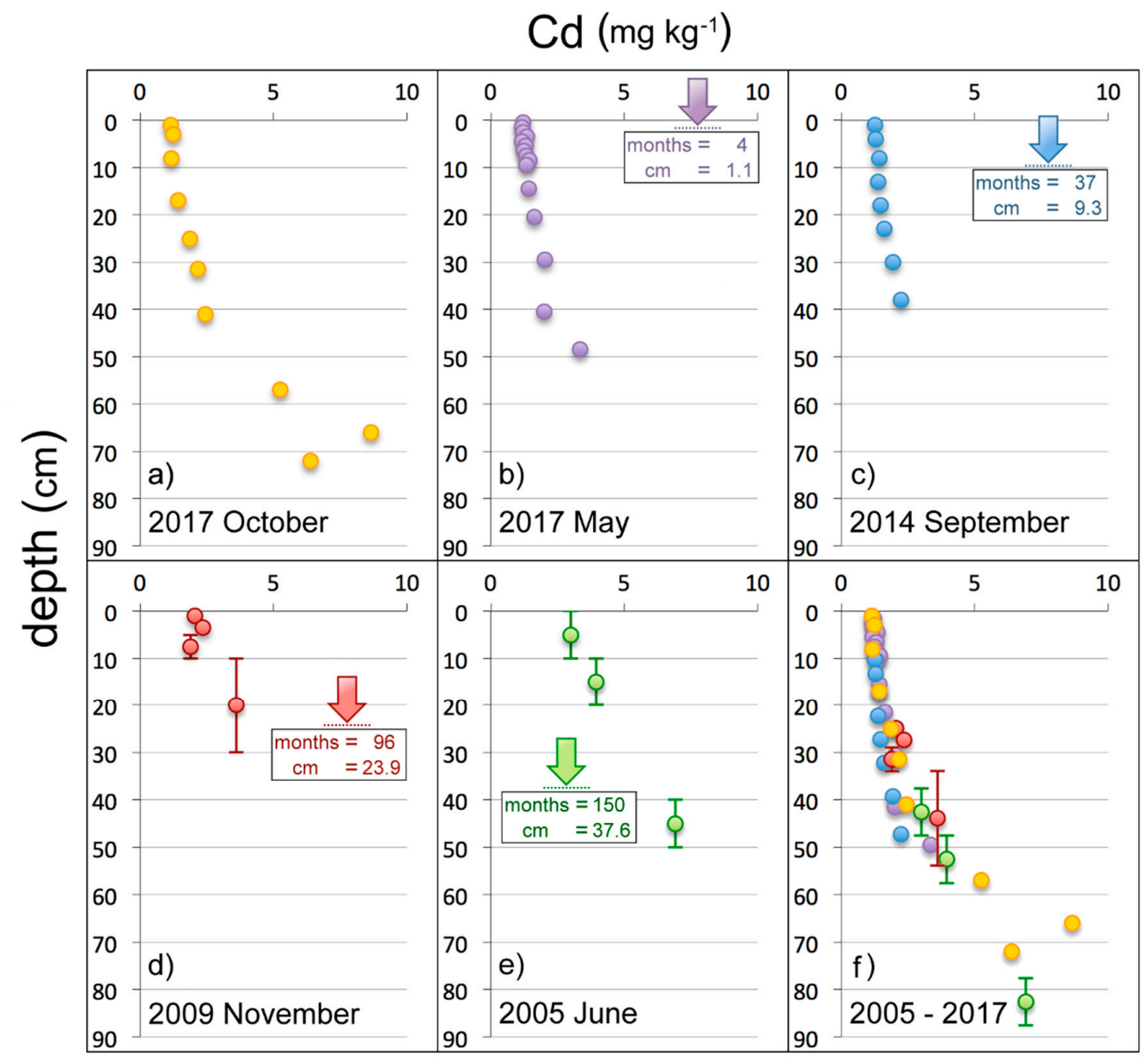

Figure A4. Cadmium concentration profiles in cores collected at site 2, at the different dates. The obtained overall profile (f) corresponds to a sedimentation rate of $3.0 \mathrm{~cm}$ year ${ }^{-1}$. Arrows (b-e) indicate the position of the top of the core after the shift; elapsed time between core collection and October 2017 (a) are indicated, and the resulting shift down-core (in cm). Vertical bars indicate sampled intervals if larger than $2 \mathrm{~cm}$. 


\section{Appendix B. Model Estimating the Contribution of Internal Sources of Metal Contaminants to Venice Canal Sediments}

Direct comparison of contaminant concentrations in lagoon ( $0-5 \mathrm{~cm}$ layer) and canal (deposited in the 2005-2017 period) sediments is difficult due to the different sediment grain-size compositions in the two settings. The fine fraction of sediments tends to be much richer in both trace metals and iron. In a previous study [27], normalisation with reference to Fe was successfully used as a surrogate of the clay or fine silt fraction for the purpose of comparing trace metal concentrations in various types of sediment in the Venice Lagoon. The locations of the lagoon sediment sampling sites selected for comparison in the present study are shown in Figure A5.

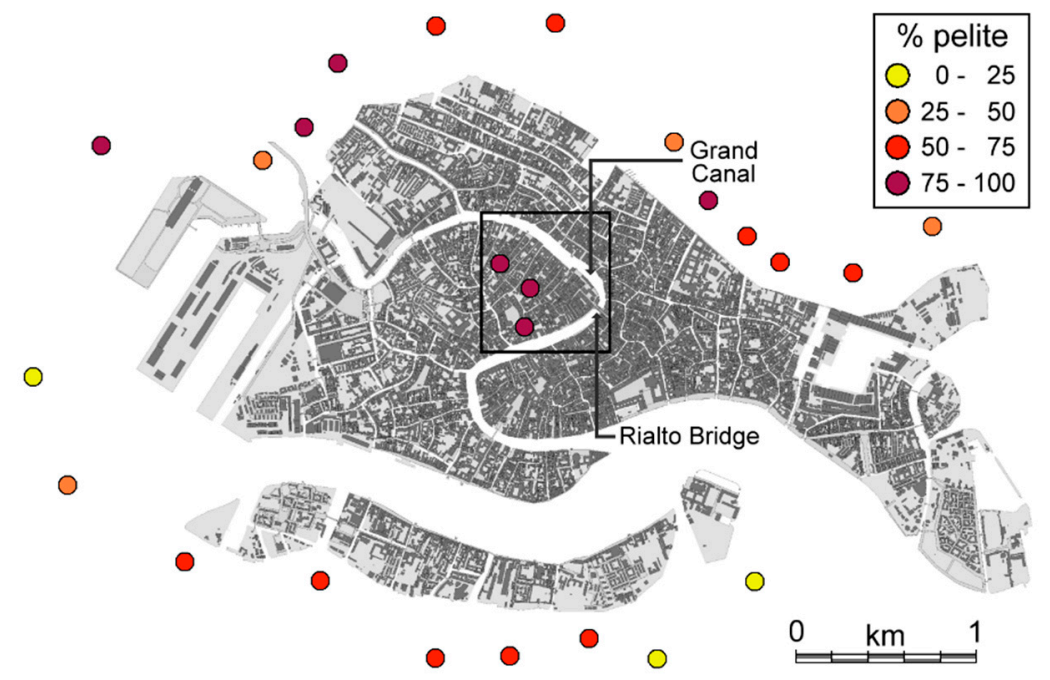

Figure A5. Sites surrounding Venice selected for comparison of metal concentrations in lagoon and city canal sediments (data from reference [27]). The locations of the three investigated sites in the canal network are also shown. Percentages of pelite (diameter $<63 \mu \mathrm{m}$ ) refer to the $0-5 \mathrm{~cm}$ sediment layer.

To estimate the share of trace metals in canal sediments attributable to internal sources, concentrations were plotted against Fe concentrations. In general, the plots revealed a good correlation between trace metals and $\mathrm{Fe}$ in lagoon sediments and a weaker or no correlation in canal sediments.

Two types of relationship were found; some trace metals showed similar regression slopes and intercepts for the lagoon and canal (e.g., As in Figure A6a, but also Ni and Cr). Other trace metals showed no correlation or only weak correlations for canal sediments, but the determination coefficients for lagoon sediments remained high (e.g., $\mathrm{Cu}$ in Figure $\mathrm{A} 6 \mathrm{~b}$, but also $\mathrm{Pb}, \mathrm{Zn}, \mathrm{Hg}$ ). By extrapolating regression lines for the lagoon sediments to the mean Fe concentration in the canals, the expected concentration of trace elements in particles delivered from the lagoon to the canals can be obtained. The ratio of the metal concentrations expected in particles originating from lagoon sediments to the mean measured concentration in canal sediments makes it possible to estimate the relative importance of internal and external sources (Table 2 in the main text). Table A1 shows the regression parameters used in the calculations, with associated errors. The obtained values are not necessarily representative for the whole canal network, as the three examined sites are located near the centre of the historic city. 

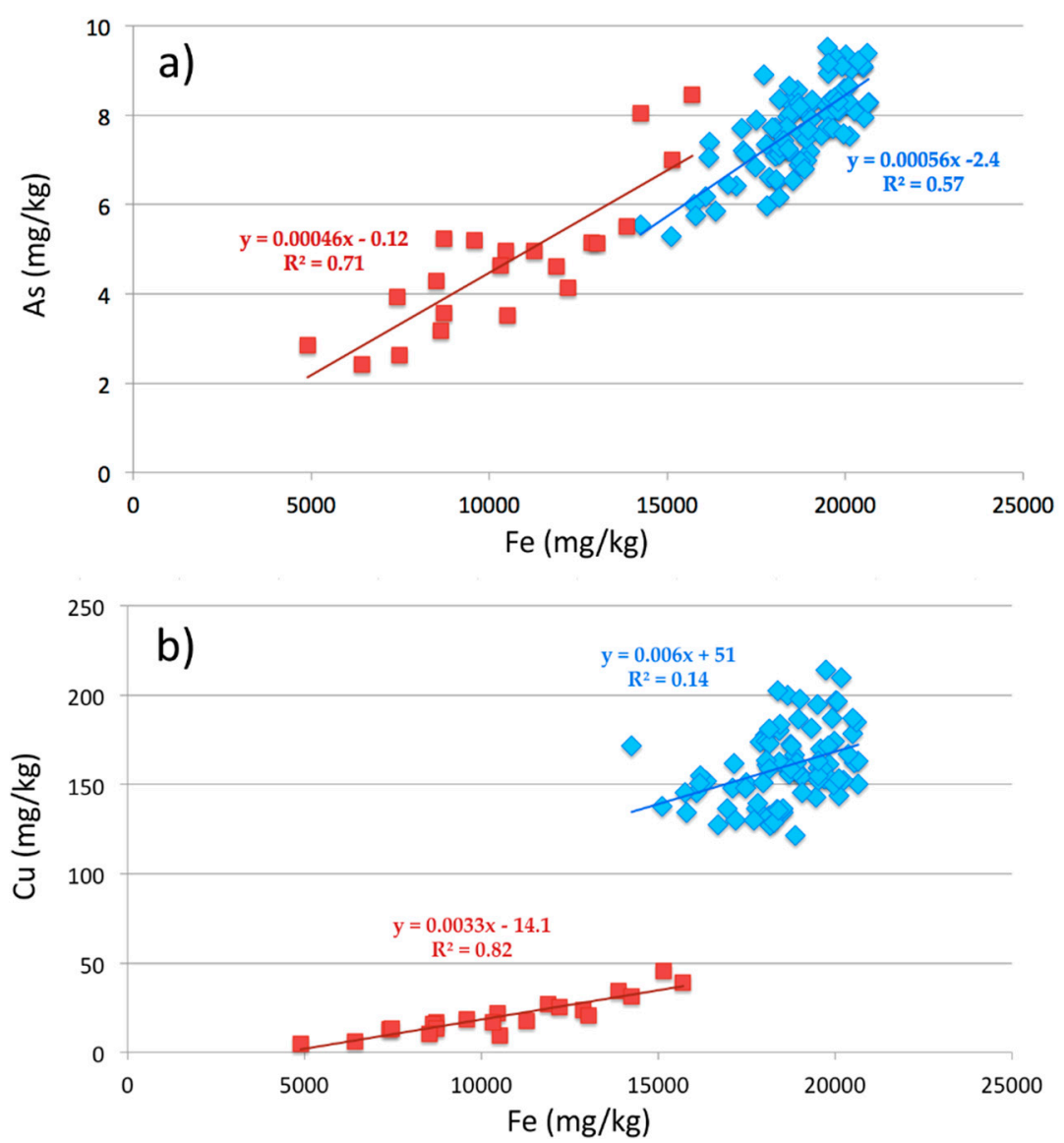

Figure A6. Plots of Fe versus As (a) and Fe versus $\mathrm{Cu}(\mathbf{b})$ for lagoon sediments (red squares) and canal sediments (blue diamonds). The plots represent the type of distribution for contaminants, which (a) derive from internal sources only to a small degree and (b) have a strong internal component.

Table A1. Mean concentrations of trace elements in canal sediments and the linear regression parameters of trace metals vs. Fe concentrations in lagoon sediments used to infer the contribution of internal sources of metals (Table 2 in the main text).

\begin{tabular}{ccccccccc}
\hline & $\mathbf{A s}$ & $\mathbf{C r}$ & $\mathbf{C u}$ & $\mathbf{H g}$ & $\mathbf{N i}$ & $\mathbf{P b}$ & $\mathbf{Z n}$ & $\mathbf{F e}$ \\
\hline Mean canals & 7.73 & 26.17 & 161.17 & 2.11 & 18.85 & 64.44 & 313.96 & 18,640 \\
Std. deviation & 0.99 & 3.22 & 21.81 & 0.34 & 2.31 & 10.36 & 43.51 & 1359 \\
\hline R2 & 0.71 & 0.88 & 0.82 & 0.59 & 0.87 & 0.79 & 0.77 & $-51,237$ \\
Intercept & -0.116 & -1593 & $-14,422$ & -0.27 & -0.685 & -6088 & $1.42 \times 10^{-2}$ \\
Slope & $4.59 \times 10^{-4}$ & $1.17 \times 10^{-3}$ & $3.28 \times 10^{-3}$ & $9.75 \times 10^{-5}$ & $8.53 \times 10^{-4}$ & $2.01 \times 10^{-3}$ & 1.42 .37 \\
Modelled value & 8.43 & 20.15 & 46.66 & 1.55 & 15.21 & 31.40 & 213.37 \\
Std. error & 2.00 & 2.86 & 10.39 & 0.55 & 2.21 & 7.07 & 53.30 & \\
\hline
\end{tabular}

Model assumptions:

1. The contribution of Fe from internal sources is negligible in comparison to the natural iron content in lagoon sediments. This assumption was confirmed by testing the relationship between the $<16 \mu \mathrm{m}$ fraction and Fe content in lagoon and canal sediments. For canals, the expected Fe concentrations obtained from regressions were only marginally lower than the measured concentrations.

2. Trace metal concentrations in selected lagoon sediments around Venice are not affected by the export of contaminants from the city canals. Although this cannot be totally excluded at some sites, metal concentrations were not higher in sites near the city than more distant points of the lagoon. The canals act as a sink rather than a source of small particles and associated metals. 


\section{Appendix C. Copper from Antifouling Paints}

The passive release of $\mathrm{Cu}$ from antifouling paints has been estimated by numerous studies and varies widely from 0.5 to $87 \mu \mathrm{g} \mathrm{cm}^{-2} \mathrm{day}^{-1}$ [57-63]. There is a general agreement that strong $\mathrm{Cu}$ release occurs during the first few weeks after the paint's immersion in water, before decreasing and stabilising at 4 to $12 \mu \mathrm{g} \mathrm{cm}{ }^{2}$ day $^{-1}[58,61,62]$. Estimates depend on the type of antifouling paint, method of measurement and water salinity.

Conservatively assuming $\mathrm{Cu}$ release from antifouling paints to be $4 \mu \mathrm{g} \mathrm{cm}^{-2} \mathrm{day}^{-1}$, the total flux to water in the canals $(\mathrm{F})$ is estimated as follows:

$$
\mathrm{F}=\mathrm{r} \times \mathrm{s} \times \mathrm{n} \times \mathrm{f}_{\mathrm{Cu}} \times \mathrm{S}^{-1},
$$

where:

$\mathrm{r}$-specific release rate $=4 \mu \mathrm{g} \mathrm{cm}^{-2}$ day $^{-1}=1457 \mu \mathrm{g} \mathrm{cm}^{-2}$ year $^{-1}$;

$\mathrm{s}$ - average hull surface of boats present in canals $=1 \times 10^{5} \mathrm{~cm}^{2}$;

$\mathrm{n}$-number of boats in Venice $=8 \times 10^{3}$ (from https://www.comune.venezia.it/it/content/spazi-acqueionline-baris, consulted on 15 April 2020);

S-surface of canals $=6.8 \times 10^{9} \mathrm{~cm}^{2}$;

$\mathrm{f}_{\mathrm{Cu}}$-proportion of boat surface covered with Cu-based antifouling paints $=0.7$ to 1 (This is not known for the Venice region. By analogy with Germany, the probable value is 0.7 [63]).

Under these assumptions, the total specific flux is $\mathrm{F}=129$ to $171 \mu \mathrm{g} \mathrm{cm}^{-2} \mathrm{year}^{-1}$.

The $\mathrm{Cu}$ flux to sediments from internal sources $\left(\mathrm{F}_{\mathrm{s}}\right)$ is calculated as follows:

$$
\mathrm{F}_{\mathrm{S}}=(1-\Phi) \times \rho \times \mathrm{d} \times \mathrm{C}_{\mathrm{t}} \times \mathrm{f},
$$

where:

$\Phi$ —sediment porosity $=0.67$;

$\rho$-sediment dry density $=2.5 \mathrm{~g} \mathrm{~cm}^{-3}$;

$\mathrm{d}$-sediment deposition rate in canals $=3 \mathrm{~cm}_{\text {year }}{ }^{-1}$;

$\mathrm{C}_{\mathrm{t}}$-mean total $\mathrm{Cu}$ concentration in canal sediments $=161 \mu \mathrm{g} \mathrm{g}^{-1}$;

$\mathrm{f}$ - proportion of $\mathrm{Cu}$ originating from internal sources $=0.71$ (see main text).

Using these values, $F_{\mathrm{S}}=282 \mu \mathrm{g} \mathrm{cm}^{-2}$ year ${ }^{-1}$.

Thus, the release of $\mathrm{Cu}$ from antifouling paints $\left(\mathrm{F} / \mathrm{F}_{\mathrm{S}}\right)$ is estimated to account for between 46 and $61 \%$ of the internal $\mathrm{Cu}$ flux to recent sediments.

\section{References}

1. Nriagu, J.O.; Pacyna, J.M. Quantitative assessment of worldwide contamination of air, water and soils by trace metals. Natural 1988, 333, 134-139. [CrossRef]

2. Dat, N.-D.; Chang, M.B. Review on characteristics of PAHs in atmosphere, anthropogenic sources and control technologies. Sci. Total. Environ. 2017, 609, 682-693. [CrossRef] [PubMed]

3. Church, T.; Sommerfield, C.; Velinsky, D.; Point, D.; Benoit, C.; Amouroux, D.; Plaa, D.; Donard, O. Marsh sediments as records of sedimentation, eutrophication and metal pollution in the urban Delaware Estuary. Mar. Chem. 2006, 102, 72-95. [CrossRef]

4. Feng, H.; Cochran, J.K.; Lwiza, H.; Brownawell, B.J.; Hirschberg, D.J. Distribution of heavy metal and PCB contaminants in the sediments of an urban estuary: The Hudson River. Mar. Environ. Res. 1998, 45, 69-88. [CrossRef]

5. Ip, C.; Li, X.-D.; Zhang, G.; Farmer, J.; Wai, O.; Li, Y. Over one hundred years of trace metal fluxes in the sediments of the Pearl River Estuary, South China. Environ. Pollut. 2004, 132, 157-172. [CrossRef]

6. Kelderman, P. Pollution assessment of the canal sediments in the city of Delft (the Netherlands). Water Res. 2000, 34, 936-944. [CrossRef] 
7. Lindstrom, M.; Jönsson, A.; Brolin, A.A.; Hakanson, L. Heavy Metal Sediment Load from the City of Stockholm. Water Air Soil Pollut. Focus 2001, 1, 103-118. [CrossRef]

8. Singh, M.; Müller, G.; Singh, I.B. Heavy Metals in Freshly Deposited Stream Sediments of Rivers Associated with Urbanisation of the Ganga Plain, India. Water Air Soil Pollut. 2002, 141, 35-54. [CrossRef]

9. Andersson, M.; Klug, M.; Eggen, O.A.; Ottesen, R.T. Polycyclic aromatic hydrocarbons (PAHs) in sediments from lake Lille Lungegårdsvannet in Bergen, western Norway; appraising pollution sources from the urban history. Sci. Total. Environ. 2014, 470, 1160-1172. [CrossRef]

10. Patrolecco, L.; Ademollo, N.; Capri, S.; Pagnotta, R.; Polesello, S. Occurrence of priority hazardous PAHs in water, suspended particulate matter, sediment and common eels (Anguilla anguilla) in the urban stretch of the River Tiber (Italy). Chemosphere 2010, 81, 1386-1392. [CrossRef]

11. Pérez-Fernández, B.; Viñas, L.; Franco, M.Á.; Bargiela, J. PAHs in the Ría de Arousa (NW Spain): A consideration of PAHs sources and abundance. Mar. Pollut. Bull. 2015, 95, 155-165. [CrossRef]

12. Tu, Y.; Ou, J.; Tsang, D.C.; Dong, C.; Chen, C.; Kao, C.-M. Source identification and ecological impact evaluation of PAHs in urban river sediments: A case study in Taiwan. Chemosphere 2018, 194, 666-674. [CrossRef]

13. Apitz, S.E.; Barbanti, A.; Bocci, M.; Carlin, A.; Montobbio, L.; Bernstein, A.G. The sediments of the Venice Lagoon (Italy) evaluated in a screening risk assessment approach: Part II—Lagoon sediment quality compared to hot spots, regional, and international case studies. Integr. Environ. Assess. Manag. 2007, 3, 415-438. [CrossRef] [PubMed]

14. Taylor, K.G.; Owens, P.N. Sediments in urban river basins: a review of sediment-contaminant dynamics in an environmental system conditioned by human activities. J. Soils Sediments 2009, 9, 281-303. [CrossRef]

15. Ministero dell'Ambiente. Criteri di Sicurezza Ambientale per gli Interventi di Escavazione, Trasporto e Reimpiego dei Fanghi Estratti dai Canali di Venezia (Art. 4, Comma 6, Legge 330/91); Protocollo Tecnico, Italian Ministry of the Environment: Rome, Italy, 1993; 23p. (In Italian)

16. Zonta, R.; Zaggia, L.; Collavini, F.; Costa, F.; Scattolin, M. Sediment contamination assessment of the Venice canal network (Italy). In Flooding and Environmental Challenges for Venice and its Lagoon: State of Knowledge; Fletcher, C., Spencer, T., Eds.; Cambridge University Press: Cambridge, UK, 2005; pp. 603-615.

17. Gardin, P. La ripresa dello scavo dei rii. In Venezia la Città dei Rii; Unesco, I., Ed.; Cierre Edizioni: Verona, Italy, 1999; pp. 91-105. (In Italian)

18. Amos, C.L.; Umgiesser, G.; Ferrarin, C.; Thompson, C.; Whitehouse, R.; Sutherland, T.; Bergamasco, A. The erosion rates of cohesive sediments in Venice lagoon, Italy. Cont. Shelf Res. 2010, 30, 859-870. [CrossRef]

19. Cassin, D.; Dominik, J.; Botter, M.; Zonta, R. PAH and PCB contamination in the sediments of the Venice Lagoon (Italy) before the installation of the MOSE flood defence works. Environ. Sci. Pollut. Res. 2018, 25, 24951-24964. [CrossRef] [PubMed]

20. Defendi, V.; Kovacevic, V.; Arena, F.; Zaggia, L. Estimating sediment transport from acoustic measurements in the Venice Lagoon inlets. Cont. Shelf Res. 2010, 30, 883-893. [CrossRef]

21. Ghezzo, M.; Sarretta, A.; Sigovini, M.; Guerzoni, S.; Tagliapietra, D.; Umgiesser, G. Modeling the inter-annual variability of salinity in the lagoon of Venice in relation to the water framework directive typologies. Ocean Coast. Manag. 2011, 54, 706-719. [CrossRef]

22. Sarretta, A.; Pillon, S.; Molinaroli, E.; Guerzoni, S.; Fontolan, G. Sediment budget in the Lagoon of Venice, Italy. Cont. Shelf Res. 2010, 30, 934-949. [CrossRef]

23. Sfriso, A.A.; Facca, C. Distribution and production of macrophytes and phytoplankton in the lagoon of Venice: comparison of actual and past situation. Hydrobiologia 2007, 577, 71-85. [CrossRef]

24. Solidoro, C.; Bandelj, V.; Bernardi Aubry, F.; Camatti, E.; Ciavatta, S.; Cossarini, G.; Facca, C.; Franzoi, P.; Libralato, S.; Melaku Canu, D.; et al. Response of the Venice Lagoon ecosystem to natural and anthropogenic pressures over the last 50 years. In Coastal Lagoons: Critical Habitats of Environmental Change; Kennish, M.J., Paerl, H.W., Eds.; CRC Press Boca Raton: Boca Raton FL, USA, 2010; pp. 483-511.

25. Umgiesser, G.; Canu, D.M.; Cucco, A.; Solidoro, C. A finite element model for the Venice Lagoon. Development, set up, calibration and validation. J. Mar. Syst. 2004, 51, 123-145. [CrossRef]

26. Zonta, R.; Costa, F.; Collavini, F.; Zaggia, L. Objectives and structure of the DRAIN project: An extensive study of the delivery from the drainage basin of the Venice Lagoon (Italy). Environ. Int. 2005, 31, 923-928. [CrossRef] [PubMed] 
27. Zonta, R.; Botter, M.; Cassin, D.; Bellucci, L.G.; Pini, R.; Dominik, J. Sediment texture and metal contamination in the Venice Lagoon (Italy): A snapshot before the installation of the MOSE system. Estuar. Coast. Shelf Sci. 2018, 205, 131-151. [CrossRef]

28. Zuliani, A.; Zaggia, L.; Collavini, F.; Zonta, R. Freshwater discharge from the drainage basin to the Venice Lagoon (Italy). Environ. Int. 2005, 31, 929-938. [CrossRef]

29. Umgiesser, G.; Zampato, L. Hydrodynamic and salinity modeling of the Venice channel network with coupled 1-D-2-D mathematical models. Ecol. Model. 2001, 138, 75-85. [CrossRef]

30. Coraci, E.; Umgiesser, G.; Zonta, R. Hydrodynamic and sediment transport modelling in the canals of Venice (Italy). Estuar. Coast. Shelf Sci. 2007, 75, 250-260. [CrossRef]

31. Zonta, R.; Cochran, J.K.; Collavini, F.; Costa, F.; Scattolin, M.; Zaggia, L. Sediment and heavy metal accumulation in a small canal, Venice, Italy. Aquat. Ecosyst. Health Manag. 2005, 8, 63-71. [CrossRef]

32. Blomquist, S. Quantitative sampling of soft-bottom sediments: problems and solutions. Mar. Ecol. Prog. Ser. 1991, 72, 295-304. [CrossRef]

33. Dück, Y.; Lorke, A.; Jokiel, C.; Gierse, J. Laboratory and field investigations on freeze and gravity core sampling and assessment of coring disturbances with implications on gas bubble characterization. Limnol. Oceanogr. Methods 2019, 17, 585-606. [CrossRef]

34. Guyard, H.; Chapron, E.; St-Onge, G.; Anselmetti, F.S.; Arnaud, F.; Magand, O.; Francus, P.; Mélières, M.-A. High-altitude varve records of abrupt environmental changes and mining activity over the last 4000 years in the Western French Alps (Lake Bramant, Grandes Rousses Massif). Quat. Sci. Rev. 2007, 26, 2644-2660. [CrossRef]

35. St-Onge, G.; Mulder, T.; Francus, P.; Long, B. Chapter Two Continuous Physical Properties of Cored Marine Sediments. In Earth and Life Processes Discovered from Subseafloor Environments-A Decade of Science Achieved by the Integrated Ocean Drilling Program (IODP); Elsevier BV: Amsterdam, The Netherlands, 2007; Volume 1, pp. $63-98$.

36. Percival, J.B.; Lindsay, P.J. Measurement of physical properties of sediments. In Manual of Physico-Chemical Analysis of Aquatic Sediments; Mudrock, A., Azcue, J.M., Mudrock, P., Eds.; CRC Press: Boca Raton, FL, USA, 1997; pp. 7-45.

37. Ng, K.C.; Whitten, W.B.; Arnold, S.; Ramsey, J.M. Digital chemical analysis of dilute microdroplets. Anal. Chem. 1992, 64, 2914-2919. [CrossRef]

38. Wentworth, C.K. A Scale of Grade and Class Terms for Clastic Sediments. J. Geol. 1922, 30, 377-392. [CrossRef]

39. United States Environmental Protection Agency. Method 3051A (SW-846): Microwave Assisted Acid Digestion of Sediments, Sludges, and Oils, Revision 1; United States Environmental Protection Agency: Washington, DC, USA, 2007; pp. 1-30.

40. United States Environmental Protection Agency. Method 200.7: Determination of Metals and Trace Elements in Water and Wastes by Inductively Coupled Plasma-Atomic Emission Spectrometry, Revision 4.4; United States Environmental Protection Agency: Cincinnati, OH, USA, 1994; pp. 1-58.

41. United States Environmental Protection Agency. Method 245.1: Determination of Mercury in Water by Cold Vapor Atomic Absorption Spectrometry, Revision 3.0; United States Environmental Protection Agency: Cincinnati, OH, USA, 1994; pp. 1-18.

42. United States Environmental Protection Agency. Method 3546: Microwave Extraction, Revision 0; United States Environmental Protection Agency: Washington, DC, USA, 2007; pp. 1-13.

43. Fossato, V.U.; Campesan, G.; Craboledda, L.; Dolci, F.; Stocco, G. Organic micropollutants and trace metals in water and suspended particulate matter. In The Venice Lagoon Ecosystem; Lasserre, P., Marzollo, A., Eds.; Unesco: Paris, France, 1996; pp. 81-96.

44. Fossato, V.U.; Campesan, G.; Dolci, F.; Stocco, G. Trends in chlorinated hydrocarbons and heavy metals in sediments of Venetian canals. Rapp. Comm. Int. Mer Méditerr 1998, 35, 258-259.

45. United States Environmental Protection Agency. Method 8100: Polynuclear Aromatic Hydrocarbons, Revision 0; United States Environmental Protection Agency: Washington, DC, USA, 1986; pp. 1-10.

46. Ibe, A.; Kullenberg, G. Quality Assurance/Quality Control (QA/QC) regime in marine pollution monitoring programmes: The GIPME perspective. Mar. Pollut. Bull. 1995, 31, 209-213. [CrossRef]

47. United States Environmental Protection Agency. QA/QC Guidance for Sampling and Analysis of Sediments, Water, and Tissues for Dredged Material Evaluations. Chemical Evaluations; EPA 823-B-95-001; United States Environmental Protection Agency: Washington, DC, USA, 1995; pp. 1-131. 
48. International Atomic Energy Agency. World-Wide and Regional Rntercomparison on the Determination of Organochlorine Compounds, Polybrominated Diphenyl Ethers and Petroleum Hydrocarbons in IAEA-459 Sediment Sample; International Atomic Energy Agency: Vienna, Austria, 2012; pp. 1-149.

49. Long, E.R.; Macdonald, D.D.; Smith, S.L.; Calder, F.D. Incidence of adverse biological effects within ranges of chemical concentrations in marine and estuarine sediments. Environ. Manag. 1995, 19, 81-97. [CrossRef]

50. Berto, D.; Brusà, R.B.; Cacciatore, F.; Covelli, S.; Rampazzo, F.; Giovanardi, O.; Giani, M. Tin free antifouling paints as potential contamination source of metals in sediments and gastropods of the southern Venice lagoon. Cont. Shelf Res. 2012, 45, 34-41. [CrossRef]

51. Boller, M.; Steiner, M. Diffuse emission and control of copper in urban surface runoff. Water Sci. Technol. 2002, 46, 173-181. [CrossRef]

52. Yunker, M.B.; Macdonald, R.W. Alkane and PAH depositional history, sources and fluxes in sediments from the Fraser River Basin and Strait of Georgia, Canada. Org. Geochem. 2003, 34, 1429-1454. [CrossRef]

53. United States Environmental Protection Agency. Provisional Guidance for Quantitative Risk Assessment of Polycyclic Aromatic Hydrocarbons; EPA/600/R-93/089; United States Environmental Protection Agency: Washington, DC, USA, 1993; pp. 1-28.

54. Hao, X.; Li, J.; Yao, Z. Changes in PAHs levels in edible oils during deep-frying process. Food Control. 2016, 66, 233-240. [CrossRef]

55. Boudreau, B.P.; Algar, C.; Johnson, B.D.; Croudace, I.W.; Reed, A.; Furukawa, Y.; Dorgan, K.M.; Jumars, P.A.; Grader, A.S.; Gardiner, B.S. Bubble growth and rise in soft sediments. Geology 2005, 33, 517. [CrossRef]

56. Liu, L.; De Kock, T.; Wilkinson, J.; Cnudde, V.; Xiao, S.; Buchmann, C.; Uteau, D.; Peth, S.; Lorke, A. Methane Bubble Growth and Migration in Aquatic Sediments Observed by X-ray $\mu$ CT. Environ. Sci. Technol. 2018, 52, 2007-2015. [CrossRef] [PubMed]

57. Valkirs, A.; Seligman, P.F.; Haslbeck, E.; Caso, J.S. Measurement of copper release rates from antifouling paint under laboratory and in situ conditions: implications for loading estimation to marine water bodies. Mar. Pollut. Bull. 2003, 46, 763-779. [CrossRef]

58. Schiff, K.; Diehl, D.; Valkirs, A. Copper emissions from antifouling paint on recreational vessels. Mar. Pollut. Bull. 2004, 48, 371-377. [CrossRef] [PubMed]

59. Finnie, A.A. Improved estimates of environmental copper release rates from antifouling products. Biofouling 2006, 22, 279-291. [CrossRef] [PubMed]

60. Sandberg, J.; Wallinder, I.O.; Leygraf, C.; Virta, M. Release and chemical speciation of copper from anti-fouling paints with different active copper compounds in artificial seawater. Mater. Corros. 2007, 58, 165-172. [CrossRef]

61. Earley, P.; Swope, B.L.; Barbeau, K.; Bundy, R.; McDonald, J.A.; Rivera-Duarte, I. Life cycle contributions of copper from vessel painting and maintenance activities. Biofouling 2013, 30, 51-68. [CrossRef] [PubMed]

62. Lagerström, M.; Lindgren, F.; Holmqvist, A.; Dahlström, M.; Ytreberg, E. In situ release rates of Cu and Zn from commercial antifouling paints at different salinities. Mar. Pollut. Bull. 2018, 127, 289-296. [CrossRef]

63. Daehne, D.; Fürle, C.; Thomsen, A.; Watermann, B.; Feibicke, M. Antifouling biocides in German marinas: Exposure assessment and calculation of national consumption and emission. Integr. Environ. Assess. Manag. 2017, 13, 892-905. [CrossRef]

(C) 2020 by the authors. Licensee MDPI, Basel, Switzerland. This article is an open access article distributed under the terms and conditions of the Creative Commons Attribution (CC BY) license (http://creativecommons.org/licenses/by/4.0/). 